TITLE:

\title{
Morphological transitions for pore water and pore air during drying and wetting processes in partially saturated sand
}

\section{AUTHOR(S):}

Kido, Ryunosuke; Higo, Yosuke; Takamura, Fukushi; Morishita, Ryoichi; Khaddour, Ghonwa; Salager, Simon

\section{CITATION:}

Kido, Ryunosuke ... [et al]. Morphological transitions for pore water and pore air during drying and wetting processes in partially saturated sand. Acta Geotechnica 2020, 15: 1745-1761

\section{ISSUE DATE:}

2020-07

URL:

http://hdl.handle.net/2433/245800

\section{RIGHT:}

This is a post-peer-review, pre-copyedit version of an article published in 'Acta Geotechnica'. The final authenticated version is available online at: https://doi.org/10.1007/s11440-020-00939-3; The full-text file will be made open to the public on 19 February 2021 in accordance with publisher's 'Terms and Conditions for Self-Archiving'.; この論文は出版社 版でありません。引用の際には出版社版をご確認ご利用ください。; This is not the published version. Please cite only the published version. 


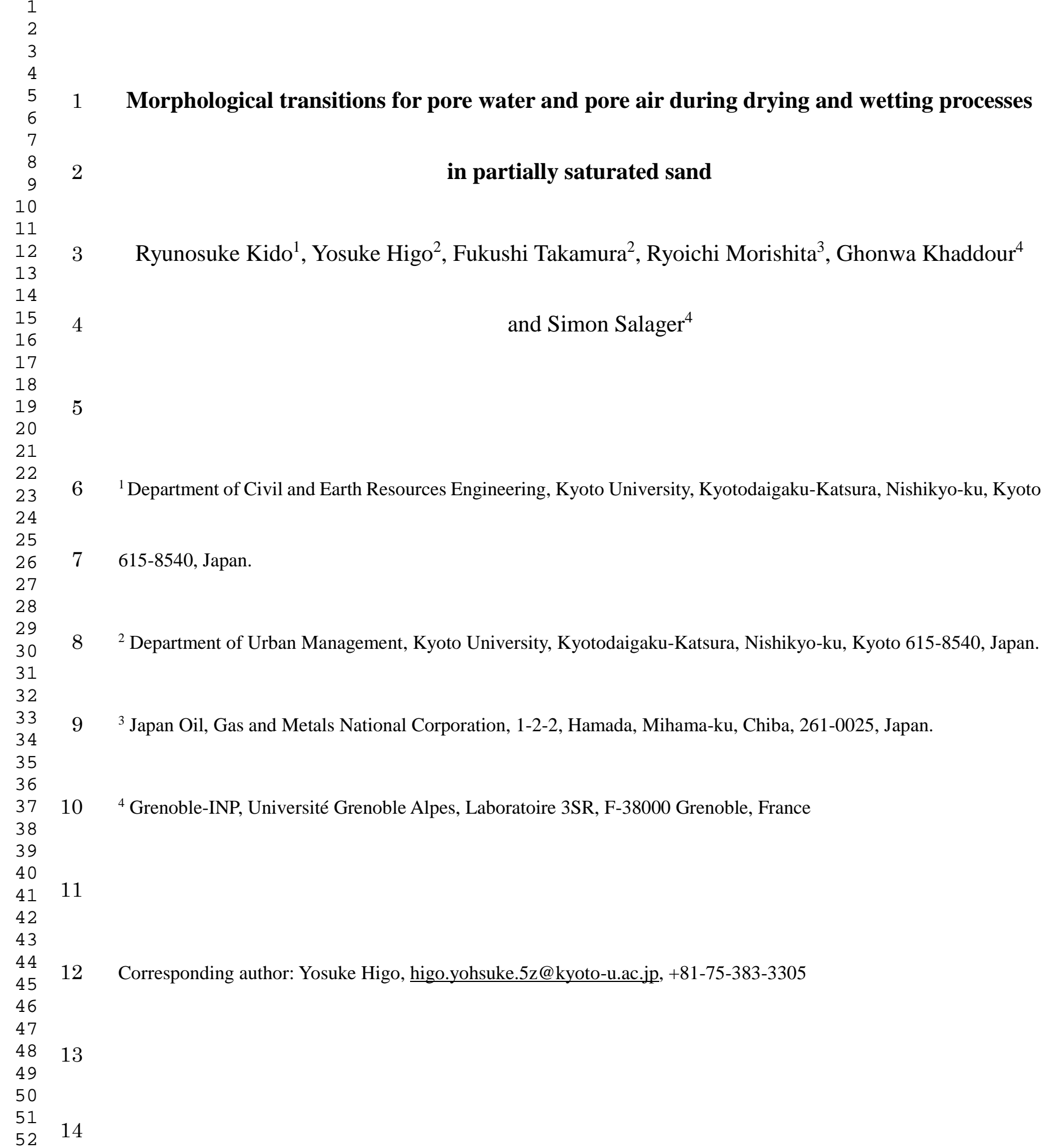

\section{Morphological transitions for pore water and pore air during drying and wetting processes}

\section{in partially saturated sand}

3 Ryunosuke Kido ${ }^{1}$, Yosuke Higo ${ }^{2}$, Fukushi Takamura ${ }^{2}$, Ryoichi Morishita ${ }^{3}$, Ghonwa Khaddour ${ }^{4}$ and Simon Salager ${ }^{4}$

$6 \quad{ }^{1}$ Department of Civil and Earth Resources Engineering, Kyoto University, Kyotodaigaku-Katsura, Nishikyo-ku, Kyoto

7 615-8540, Japan.

$8 \quad{ }^{2}$ Department of Urban Management, Kyoto University, Kyotodaigaku-Katsura, Nishikyo-ku, Kyoto 615-8540, Japan.

$9 \quad{ }^{3}$ Japan Oil, Gas and Metals National Corporation, 1-2-2, Hamada, Mihama-ku, Chiba, 261-0025, Japan.

$10{ }^{4}$ Grenoble-INP, Université Grenoble Alpes, Laboratoire 3SR, F-38000 Grenoble, France

12 Corresponding author: Yosuke Higo, higo.yohsuke.5z@kyoto-u.ac.jp, +81-75-383-3305 


\section{Abstract}

16 Water retention characteristics are important for modeling the mechanical and hydraulic behavior of partially 17 saturated sand. It is well known that the soil water characteristic curve shows hysteresis during drying and wetting 18 processes. For a better understanding of the water retention characteristics of partially saturated soil, a microscopic 19 investigation of the morphological transitions for the pore water phase and the pore air phase, such as volume 20 distribution, spatial distribution and continuity during drying and wetting processes, is crucial. In the present study, 21 different water retention states of a partially saturated sand were visualized during water retention tests using 22 microfocus x-ray computed tomography (CT). The CT images obtained from the tests were segmented into the soil 23 particle phase, the pore water phase and the pore air phase. Then, a series of image processing, erosion, dilation and 24 cluster labeling, was applied to the images in this order to quantify the cluster volume distributions, the number of 25 clusters and the continuity of both the pore water phase and the pore air phase. The morphological transitions for the 26 pore air phase and the pore water phase, subjected to decreasing and increasing degrees of saturation, were revealed 27 using the results of the image processing, and then the water retention states were characterized based on the 28 morphologies for the two phases. The influence of the morphologies on the hysteresis was discussed. 


\section{Introduction}

The relationship between suction and the degree of saturation for partially saturated soil is interpreted as the soil

water retention curve (SWRC). The SWRC is an important characteristic for the hydraulic and mechanical behavior of

partially saturated soil. Thus, a modeling of the SWRC that incorporates the effect of the hydraulic hysteresis of the

water retention characteristics into the shear strength, permeability and volume change of partially saturated soil was

developed (e.g., $[5,9,11,33,44])$. The hysteresis shown during the drying and wetting processes by the SWRC was

observed through water retention tests (e.g., $[8,13,20,43])$, and the water retention capability was found to significantly

depend on the bulk density of the soil and the particle size distribution (e.g., [10, 39]). The main causes of the hysteresis

42 have been interpreted as follows: 1) the ink-bottle effect due to irregularities in the size and connectivity of the pores

43 (e.g., [34]) and 2) the contact angle hysteresis at the interface between a liquid and a solid during the drying and wetting

44 processes (e.g., $[3,6])$. Up to now, these mechanisms at the pore scale have generally been expressed by schematic

45 illustrations (e.g., [2, 30]). For a better understanding of these mechanisms, a microscopic investigation of the water

46 retention behavior in particulate soils is important.

The purpose of the present study is to reveal the microscopic water retention behavior of partially saturated sand

using microfocus x-ray computed tomography (CT). Microfocus x-ray CT is an effective tool for nondestructively and

49 three-dimensionally visualizing the microstructures of geomaterials or porous media; it has been widely used for

50 investigating the failure mechanism of particulate soils with strain localization (e.g., $[1,7,17,37])$ and particle

51 morphological features of granular geomaterials [31]. Spatial resolution and image processing techniques for 
microfocus X-ray CT have been developed, resulting in the ability to segment the phases in an object at the microscopic

scale and to investigate the microstructural changes in soils [e.g., [36]]. For partially saturated sands, microfocus x-ray

54 CT has been applied to investigations of water retention states and the evolution of pore-scale quantities. The

55 investigations have been done through triaxial compression tests (e.g., $[17,18,21,26])$ and water retention tests (e.g.,

$56 \quad[4,16,19,20,22,24,28,29,35])$.

Changes in the degree of saturation in partially saturated soil involve morphological transitions for both water and

air in void spaces, which cause variations in the water retention states. Microscopic investigations of the morphologies

for the pore water phase and the pore air phase, and their transitions during the drying and wetting processes, provide

60 important data for classifying the water retention states and contribute to elucidating the mechanism of the hysteresis.

The morphologies of pore water for partially saturated soils, such as the shape of the liquid bridges and the distribution

of pore water, have been extensively studied. Observations of the morphologies have been done using a scanning

electron microscope (SEM) and an environmental scanning electron microscope (ESEM) (e.g., [12, 40]). Mercury

64 intrusion porosimetry (MIP) is the other approach for studying pore water morphologies based on pore space

65 morphologies (e.g., [38, 40]). Although SEM and ESEM provide high resolution images sufficient for visualizing the

66 liquid bridges, the images are limited to those that capture small portions of the sample surfaces. Recently, microfocus

67 x-ray CT with image analyses has been applied to investigate the pore water morphologies in three-dimensional

conditions (e.g., [23, 27, 32, 41, 46]). The morphologies of both pore water and pore air, and their transitions during

69 triaxial compression tests and water retention tests, need further study. In addition, the morphological transitions for 
1

2

70 pore fluids with a variation in the degree of saturation are essential for interpreting the relationship between the water

71 retention characteristics and the mechanical behavior during shearing as well as the permeability of partially saturated

72 soil (e.g., $[14,18,26,42])$.

73 In the present study, a water retention test was performed on sand, and the various water retention states subjected

74 to drying and wetting were visualized using microfocus x-ray CT. The CT images obtained in the tests were segmented

75 into the soil particle phase, the pore water phase and the pore air phase (trinarization). A series of image processing,

76 erosion, dilation and cluster labeling, was applied to the trinarized images to quantify the volume distributions, the

77 number of clusters and the continuity for the pore water phase and the pore air phase. The morphologies for the pore

78 water phase and the pore air phase at given degrees of saturation and their transitions during the drying and wetting

79 processes were clearly specified using the results of the image processing. Then, the water retention states which have

80 been schematically explained were interpreted based on the morphologies for the two phases. Through comparisons

81 of the analysis results using the images obtained at almost the same degrees of saturation during drying and wetting,

82 the influence of the morphologies for the two phases on the hysteresis was examined. 


\section{2. Material and Experimental Setup}

84 The sample used in the present study is Toyoura sand. Figure 1 shows the grain size distribution curve of Toyoura

85 sand, while the physical properties of this sand are listed in Table 1 . The diameter $D_{50}$ of Toyoura sand is $190 \mu \mathrm{m}$.

86 Figure 2 shows a schematic illustration of the test apparatus consisting of an acrylic hollow cylinder (18.0 mm in inner

87 diameter and $18.0 \mathrm{~mm}$ in height), an acrylic pedestal (35.0 $\mathrm{mm}$ in diameter), a saturated ceramic disc, a double-tube

88 burette and a water tank. The air-entry pressure of the ceramic disc was $50 \mathrm{kPa}$, which is sufficiently larger than the

89 water retention capability of Toyoura sand; thus, the suction imposed on the Toyoura sand could be controlled by the

90 ceramic disc. A loose (low bulk density) sand specimen was prepared by the water pluviation technique; namely, the

91 Toyoura sand was poured from a certain height into the hollow cylinder that was initially filled with water. The specimen

92 conditions are listed in Table 2. It is seen in the x-ray tomographic images that tiny air bubbles were trapped at the

93 initial condition. In the present study, it was assumed that the volume of trapped air bubbles was sufficiently small and

94 that the degree of saturation at the initial state was $100 \%$.

95 The water retention test in the present study was started by conducting the drying process using a negative water

96 column [45]. Suction was applied making sure the water level in the burette was lower than the top of the specimen

97 (Fig. 2); the water level in the burette was varied until equilibrium was reached (about 1 day for the studied specimen).

98 The applied suction was then seen to correspond to the water head difference between the water level in the burette and

99 the top of the specimen. A level of suction that corresponded to the air-entry pressure of Toyoura sand (2 $\mathrm{kPa})$ was

100 firstly applied and then a step-by-step increase in suction was applied up to $10 \mathrm{kPa}$ during the drying process. The 
corresponding changes in the amount of water drainage at each equilibrium were measured by a differential pressure

gauge installed on the burette. After the drying process, the wetting process was started by decreasing the suction from

$10 \mathrm{kPa}$ to $2 \mathrm{kPa}$ and then continuing to decrease it step-by-step to $0 \mathrm{kPa}$. The corresponding changes in the amount of 


\section{Image Analysis Methods}

\subsection{Trinarization}

In the present study, the soil particle phase, the pore water phase and the pore air phase in the three-dimensional

tomographic volume were segmented using the region growing method (e.g. [19]). The region growing method is a

"initial seed". Subsequently, the voxels adjacent to the initial seed are extracted as the same phase when their gray

values are smaller than the tolerance limit. To distinguish between the three phases using the region growing method,

a suitable tolerance for each phase is needed. In the CT images scanning partially saturated sand, a voxel often shares

more than two phases. Specifically, voxels sharing the soil particle phase and the pore air phase are often misidentified

for the region growing of the soil particle phase and the pore air phase were determined by taking the partial volume

effect into account in the following steps. Firstly, the gray value distributions for the soil particle phase, the pore water

phase and the pore air phase were assumed as normal distributions, while those for the three types of phases due to the

partial volume effect, namely, the voxels sharing the soil particle phase and the pore water phase, the voxels sharing

the pore water phase and the pore air phase and the voxels sharing the pore air phase and the soil particle phase, were

assumed as uniform distributions, as shown in Fig. 4. Subsequently, the superposition of the weighted gray value

distributions for the six phases was determined using the maximum likelihood estimation method so that it was close 
136 to the gray value distribution of the original CT image. Once the superposition was estimated, the level of tolerance for

extracting the pore air phase was determined as the interval between the mean value of the normal distribution for the

pore air phase and the intersection of the normal distributions for the pore air phase and the pore water phase, as shown

in Fig. 5. Similarly, the level of tolerance for extracting the soil particle phase was determined as the interval between

142 considered as the pore water phase. Prior to the trinarization, a median filter with $5^{3}$ voxels was applied to the CT

143 images obtained in the present study to reduce noise. The median filter was applied and region growing was performed

144 using the 3D image analysis software VGStudioMax3.1 (Volume Graphics GmbH). Examples of the original CT image and the trinarized image are shown in Fig. 6 in which the gray, blue and black colors denote the soil particle phase, the pore water phase and the pore air phase, respectively. 150 an acrylic cylinder by the moist tamping method. Two kinds of X-ray CT scans were performed with spatial resolutions 151 of $6.72 \mu \mathrm{m}$ (Case A) and $12.25 \mu \mathrm{m}$ (Case B). Then, the void ratio and the degree of saturation, calculated using 152 trinarization, were compared with those of the specimen. The specimen was small enough to be observed in its entirety To investigate the accuracy of the measuring volumes of the pore water phase and the pore air phase using the trinarization technique, validation work was conducted. A specimen with a height of $12 \mathrm{~mm}$, a diameter of $6 \mathrm{~mm}$, a void ratio of 0.846 and a degree of saturation of 0.662 was prepared, as shown in Fig. 7. Toyoura sand was packed in 53 even with the high spatial resolution of $6.72 \mu \mathrm{m}$. The results are listed in Table 4. The void ratio and the degree of 
saturation calculated using trinarization are close to those of the specimen in both cases. Case A shows more accurate

reasonable segmentation technique for partially saturated sand.

values than Case B, which indicates that the higher the resolution of the CT image is, the more accurate the trinarization will be. The gray value histograms for Cases A and B are shown in Figs. 8a and 8b, respectively. It is found from these figures that the shape of the superposition of the weighted distributions estimated by the maximum likelihood estimation method is similar to that of the original distribution for both cases. As shown in Fig. 8b, for Case B, the proposed technique describes the influence of the partial volume effect which leads to a relatively larger amount of frequency between the pore water phase and the soil phase. These results confirm that the proposed trinarization technique is a

The aim of this analysis was to reveal the volume distribution, continuity and numbers of assemblies for the pore

air phase and the pore water phase in partially saturated sand. In the present study, the pore air phase and the pore water

phase extracted from the trinarized volumes were divided into some assemblies with individual continuity. Hereafter,

they are referred to as "clusters" using the 3D image analysis software Avizo9.4.0 (FEI). The procedure for the morphology analysis of the pore water phase is as follows. Firstly, the pore water phase is extracted from the trinarized volume to provide the binary volume in which the blue portion is the pore water phase and the black portion is the background phase, as shown in Fig. 9b. The binary volume contains pore water voxels due to the partial volume effect 
between the soil particle phase and the pore air phase as well as the absorbed water that surrounds the soil particles.

Erosion and dilation are performed in this order to remove those voxels. Erosion is the morphological operator which combines two sets using the vector subtraction of set elements to remove the projected noises from the digital image, while dilation is the morphological operator which combines the two sets using the vector addition of set elements to fill in the voids in the digital image (e.g., [15]). A structuring element that is composed of a center voxel and the neighboring six voxels is defined for the erosion and the dilation. For the erosion, the target pore water voxel centered 177 at the structuring element is replaced with a background voxel when one of the neighboring six voxels corresponds to the background voxel. In contrast, for the dilation, the target background voxel centered at the structuring element is replaced with a pore water voxel when one of the neighboring six voxels corresponds to the pore water voxel. It is assumed that the one-voxel erosion-dilation image processing sufficiently removes the voxels due to the partial volume 182 clusterized, as shown in Fig. 9c. The separated pore water is labeled by assigning a unique number to all adjacent voxels that constitute a cluster. Each cluster exhibits a different consecutive number starting with the value 1. In Fig. 9d, each color describes a unique number for each cluster. The cluster volumes and the number of clusters are quantified by counting the number of voxels that constitute each cluster in the labeled images. 


\section{Results}

\subsection{Water retention curve}

Figure 10 describes the water retention curve. The wetting curve is located below the drying path at a given degree

191 of saturation; i.e., hysteresis is clearly observed.

The degree of saturation begins to decrease at a suction of $1.9 \mathrm{kPa}$ (point "b") to that of $9.8 \mathrm{kPa}$ (point "g") in the

drying process, while it begins to increase at a suction of $1.9 \mathrm{kPa}$ (point "h") in the wetting process. The degree of saturation at a suction of $0.0 \mathrm{kPa}$ at the end of the wetting process is less than $100 \%$, which indicates that air bubbles

195 have been trapped due to drying and wetting in this order.

\subsection{Local void ratio and degree of saturation}

In Fig. 10, the symbols from "a" to "l", except for "h" and "l", indicate the points at which the specimen is in

equilibrium, and x-ray CT scanning and trinarization were performed. Points "h" and "l" are omitted because the obtained images were of low quality due to mechanical problems. Figure 11 shows examples of the horizontal and

202 It is clearly observed that the black portion, indicating the pore air phase, increases in the drying process, whereas the vertical cross sections of the local tomography images and the trinarized images during the drying and wetting processes.

203 blue portion, indicating the pore water phase, increases in the wetting process. The local void ratio and the degree of 
saturation were quantified by counting the number of voxels for the three phases (the soil particle phase, the pore air

phase and the pore water phase) in the trinarized volumes. Figure 12 shows the local void ratios at each degree of

saturation. It is seen that the local void ratios are comparable with the global void ratios. Figure 13 shows a comparison

of the water retention curve obtained by the test and the relationship between the local degrees of saturation calculated

210 global degrees of saturation of the specimen. One of the causes is that the initial global degree of saturation, assumed

to be $100 \%$, is larger than the real one due to the trapped air bubbles. Another possible reason is that the trinarized

212 volumes contain a relatively greater amount of pore water than the other portions of the specimen, namely, the 213 heterogeneity of the degree of saturation. In addition, the degrees of saturation shown in this figure are calculated using

\subsection{Morphological transitions for pore water and pore air}

\subsubsection{Distributions of cluster volume for pore air and pore water}

219 respectively. The cluster volume used as a horizontal axis in these figures is the number of voxels that constitute each

Figures 14a and 14b show the cluster volume distribution curves (CVDCs) of the pore air and the pore water,

220 cluster, while the vertical axis is the cumulative ratio of each cluster volume to the total cluster volume, i.e., the 
proportion of clusters within a certain volume. In Fig. 14a, the pore air clusters with a volume of $10^{3}$ to $10^{5}$ voxels exist

7

at an almost water-saturated condition (points "a" and "b"). As desaturation progresses up to point "d", the cumulative volume at pore air volumes smaller than $10^{5}$ voxels becomes nearly zero and then a pore air cluster with a volume larger than $10^{6}$ voxels is observed at the cumulative volume of $100 \%$. This suggests that the pore air clusters with smaller volumes connect to each other, forming a large pore air cluster with a decreasing degree of saturation. Further desaturation up to point "g" provides a larger pore air cluster. On the contrary, a larger pore air cluster loses its volume and is divided into smaller clusters during the wetting process from points "g" to "k".

In Fig. 14b, the CVDC of the pore water exhibits an opposite trend to that of the pore air during the drying and wetting processes. A large pore water cluster exists at higher degrees of saturation and gradually loses its volume during 230 the drying process, which is finally divided into smaller pore water clusters at lower degrees of saturation. The smaller pore water clusters tend to merge together into a large pore water cluster during the wetting process. As indicated by

Fig. 14b, the cumulative volume of a pore water cluster with a volume of $10^{4}$ voxels is less than $10 \%$ at degrees of saturation higher than $28 \%$ (points without " $\mathrm{f}$ " and "g") and a pore water cluster with a volume larger than $10^{8}$ voxels 234 shows $100 \%$ cumulative volume. On the other hand, a pore water cluster with a volume of $10^{4}$ voxels shows $100 \%$ 235 cumulative volume at degrees of saturation lower than $28 \%$ (points "f" and "g"). This indicates that the volume of $10^{4}$ voxels for the pore water cluster seems to be the threshold between smaller volume clusters and a large volume cluster for Toyoura sand. The large volume cluster of the pore water phase is larger than $10^{8}$ voxels. 


\subsubsection{Continuity and number of clusters for pore air and pore water}

The maximum number of voxels that constitute a cluster, that is, the maximum volume $\left(\mathrm{V}_{\max }\right)$ of a cluster out of all

the clusters, was evaluated. Figures $15 \mathrm{a}$ and $15 \mathrm{~b}$ show the $\mathrm{V}_{\max }$ of the pore air and pore water clusters at each degree of saturation, respectively. The symbols in these figures correspond to the x-ray scanning points shown in Fig. 10. In Fig.

$24315 \mathrm{a}$, the $\mathrm{V}_{\max }$ of the pore air cluster increases from points "c" to " $\mathrm{g}$ " in the drying process and then gradually decreases 244 from points "g" to " $\mathrm{k}$ " in the wetting process. On the contrary, the $\mathrm{V}_{\max }$ of the pore water cluster decreases in the drying 245 process and increases in the wetting process, as shown in Fig. 15b. Figures 16a and 16b show the total volumes $\left(\mathrm{V}_{\text {total }}\right)$ 246 of the pore air and pore water clusters at each degree of saturation, respectively. For pore air, the $\mathrm{V}_{\text {total }}$ is larger than the 248 for the pore water at points " $\mathrm{f}$ " and "g" where the degrees of saturation are lower than $20 \%$. For the other points, the $249 \mathrm{~V}_{\text {total }}$ for both the pore air and pore water clusters is almost identical to the $\mathrm{V}_{\max }$.

251 an indicator for discussing the water retention states; it does not directly describe whether or not the pore water is 252 continuous in real soil. Figures $17 \mathrm{a}, 17 \mathrm{~b}$ and $17 \mathrm{c}$ show the labeled images of the pore water cluster with continuity of $253100.00 \%$ (point “a”), 97.26\% (point "e") and 0.10\% (point "f"), respectively. Continuity of almost 100\% means that one cluster occupies the total volume of clusters, whereas continuity of $0.10 \%$ means that the individual clusters exist 
independently and spatially. A large cluster and some smaller clusters coexist when the continuity is about $97.26 \%$, as

demonstrated in Fig. 17b. Figure 18 shows examples of pore water clusters with different volumes at point "e" where the continuity of the pore water phase is almost $97.26 \%$. The erosion-dilation image processing, aimed at removing the pore water voxels from the grain surface, possibly removes the voxels of the capillary bridges created between grains. Nevertheless, it is apparent from this figure that the pore water clusters with volumes smaller than $10^{3}$ voxels $\left(2.1 \times 10^{5}\right.$ $\mu \mathrm{m}^{3}$ ) form capillary bridges between the grains and that the clusters with a larger volume exhibit the same shape as some of the connected small clusters. If the volume of a pore water cluster is larger than $10^{4}$ voxels $\left(2.1 \times 10^{6} \mu \mathrm{m}^{3}\right)$, as shown in Fig. 18, the pore water phase becomes continuous with a volume of $10^{8}$ voxels $\left(2.1 \times 10^{10} \mu \mathrm{m}^{3}\right)$. Figures19a, $19 \mathrm{~b}$ and $19 \mathrm{c}$ show the labeled images of pore air clusters with different levels of continuity. The figures indicate that the pore air clusters exist as bubbles when the continuity is near $0 \%$ and they connect to each other to form a large pore air cluster with an increase in continuity. Figure 20 shows examples of pore air clusters with different volumes. It can 266 be seen from this figure that the pore air cluster with a volume smaller than $10^{5}$ voxels exists as a bubble, while that with a volume of $10^{6}$ voxels seems to be a continuous cluster comprising some air bubbles. In other words, a volume 268 of $10^{6}$ voxels seems to be the threshold of a morphological transition for the pore air between small volume clusters and a large volume cluster.

Figures $21 \mathrm{a}$ and $21 \mathrm{~b}$ show the relations of the global degrees of saturation with continuity for pore air and with continuity for pore water, respectively. The continuity for pore air at degrees of saturation higher than $80 \%$ is smaller than $10 \%$ and it is nearly $100 \%$ at degrees of saturation lower than $80 \%$ without point "c". On the other hand, the 
1

2

3

4

5273

6

7

8

9 10

11 283

continuity for pore water at degrees of saturation lower than $30 \%$ is almost $0 \%$ and it is almost $100 \%$ at degrees of

saturation higher than $30 \%$. In other words, pore air becomes continuous while losing the continuity of pore water in

275 the drying process, and pore water becomes continuous while losing the continuity of pore air in the wetting process.

276 It is also clearly seen in Fig. 21 that the continuity for both pore air and pore water is relatively large at degrees of saturation between $30 \%$ and $80 \%$. This indicates that the pore air phase and the pore water phase are mostly continuous during a certain range of degrees of saturation in the middle of the drying and wetting processes.

280 saturation, a lot of pore air clusters and a smaller number of pore water clusters exist. Along with lower degrees of 281 saturation, comes the tendency for a larger number of pore water clusters to exist with a decreasing number of pore air 282 clusters.

Figures $22 \mathrm{a}$ and $22 \mathrm{~b}$ show the number of clusters of pore air and pore water, respectively. At higher degrees of 


\section{Discussions}

The results of the morphology analysis for Toyoura sand, including the continuity, the cluster volume and the number of clusters for pore air and pore water, are summarized in Fig. 23. Firstly, pore air is discontinuous; therefore, smaller

pore air clusters exist at almost fully saturated conditions (points "a" and "b"). In this case, a continuous pore water

288 cluster with a large volume occupies the void spaces in the sand, as shown in Fig. 17a; smaller air bubbles are spatially

289 trapped in the void spaces, as shown in Fig. 19a.

290 As desaturation proceeds until degrees of saturation lower than the AEV (points "c", "d" and "e"), morphologies for 291 both the pore air phase and the pore water phase start to change. Specifically, discontinuous pore air clusters with 292 smaller volumes connect to each other forming a continuous pore air cluster with a large volume, as shown in Fig. 19b, 293 whereas continuous pore water begins to be separated into smaller pore water clusters, for example, as shown in Fig. 295 together in the void spaces. In the water retention state, along with lower degrees of saturation, comes a larger number 296 of pore water clusters.

297 With a further decrease in the degrees of saturation (points "f" and "g"), a continuous pore air cluster becomes larger 298 and then only discontinuous pore water clusters with smaller volumes exist. This suggests that capillary bridges exist spatially at the grain contacts, as shown in Figs. 17c and 18. In the wetting process, pore air and pore water become 
continuous with increasing degrees of saturation, after which the pore air becomes discontinuous and the pore water

becomes continuous.

The results of the morphology analysis confirmed that the morphologies for pore air and pore water in partially

two phases as the following three states: 1) a state at which discontinuous pore air (trapped air) and continuous pore

continuous pore air and discontinuous pore water (capillary bridges) coexist.

water coexist, 2) a state at which continuous pore air and continuous pore water coexist and 3) a state at which

Figure $14 \mathrm{~b}$ suggests that there is a threshold where the morphology of pore water starts to transit, i.e., discontinuous

pore water clusters with smaller volumes become a continuous pore water cluster with a large volume and vice versa.

In the present study, the threshold was, for example, about 0.6 times as large as a soil particle of Toyoura sand $\left(2.1 \times 10^{6}\right.$

$\mu \mathrm{m}^{3}$ ). Similarly, Fig. 14a suggests that there is a threshold where the morphology of pore air starts to transit, and its value was about 60 times as large as a soil particle of Toyoura sand $\left(2.1 \times 10^{8} \mu \mathrm{m}^{3}\right)$. These trends can probably be attributed to the uniformity of the pore volumes in the Toyoura sand which is a poorly graded sand. On the other hand, the threshold of pore air is not as clear as that of pore water. In other words, pore air clusters with a larger variety of volumes spatially distribute more in partially saturated sand than pore water clusters. A morphology analysis for sand transitions for both pore air and pore water. 
In cases where partially saturated sand is subjected to drying and wetting in this order, pore air and pore water

3) in this order during the drying process and states 3), 2) and 1) in this order during the wetting process. These histories

correspond to the states demonstrated in Figs. 17a, 17b and 17c during the drying process and the states demonstrated

in Figs. 17c, 17b and 17a during the wetting process. Assuming that the above water retention states correspond to

2) and 3), respectively.

A comparison of the results at similar degrees of saturation during the drying and wetting processes, given in Fig. 10,

332 saturation are similar, probably causes the hysteresis.

examines the relationship between the morphological transitions of pore fluid (pore air and pore water) and hysteresis.

Comparisons of the results at such points, e.g., "d" and "j", and "e" and "ij" in Fig. 23, confirm that both pore water and

pore air are continuous at any point. Thus, there is no significant difference in microscopic morphologies for pore air and pore water at similar degrees of saturation during the drying and wetting processes evaluated by the morphology

analysis even though the water retention curve apparently exhibits hysteresis. It is possible that the difference in the principal curvatures of the capillary bridges, which leads to different levels of suction even when the degrees of 


\section{Conclusions}

X-ray CT images, scanning different water retention states with high spatial resolution, were analyzed using a morphology analysis to investigate the volume distributions, continuity and number of clusters for pore air and pore water with a variation in the degree of saturation. Then, the morphologies for the two phases were clearly specified based on the results.

The analysis confirmed that pore air and pore water in partially saturated sand exhibit two kinds of morphologies: a continuous and large volume and discontinuous and smaller volumes. In the drying process, continuous pore water was divided into discontinuous pore water clusters, i.e., capillary bridges. In contrast, discontinuous pore air bubbles connected to each other and formed a continuous pore air cluster with a large volume. In the wetting process, the opposite behavior was observed. Based on the morphologies, the water 344 retention states were classified into three states at certain degrees of saturation: 1) the state at which discontinuous 345 pore air (trapped air) and continuous pore water coexist, 2) the state at which both pore air and pore water are 346 continuous and 3) the state at which continuous pore air and discontinuous pore water (capillary bridges) coexist.

349 apparent hysteresis; however, the morphology analysis revealed that there was no significant difference in the 350 morphologies for pore air and pore water at similar degrees of saturation during the drying and wetting processes. 
1

2

3

4

5

7

9

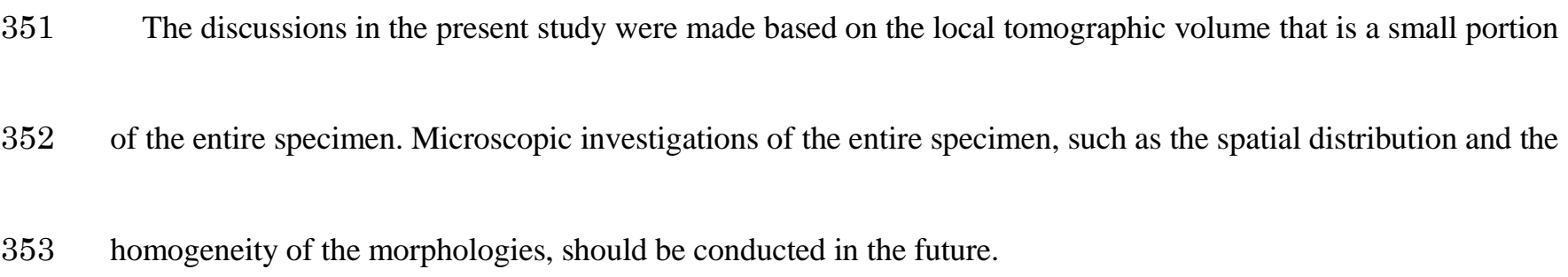

\section{$355 \quad$ Acknowledgments}

356 This research was partly supported by grants given by Tec 21, the Obayashi Foundation, SPIRITS project of Kyoto 357 University and the Japan Society for the Promotion of Science (JSPS) Grant-in-Aid for JSPS Fellows [Subject No. 358 17J06250]. The authors gratefully acknowledge the support of Mr. Takanobu Ishimura (Maxnet Co., Ltd, Japan) who 359 assisted us in performing the image analysis by using 3D image analysis software Avizo9.4.0 (FEI) in the present study. 


\section{References}

1. Andò E, Hall SA, Viggiani G, Desrues J, Bé-suelle P (2012) Grain-scale experimental investigation of localised deformation in sand: a discrete particle tracking approach. Acta Geotechnica 7(1):1-13

2. Bear J (1979) Hydraulics of groundwater. New York, McGraw-Hill:190-224

3. Blake TD, Haynes IM (1973) Contact-angle hysteresis. Progress in surface and membrane science 6:125-138

4. Bruchon JF, Pereira JM, Vandamme M, Lenoir N, Delage P, Bornert M. (2013) Full 3D investigation and characterization of capillary collapse of a loose partially saturated sand using X-ray CT. Granular Matter 15(6):783-800

5. Chiu, DF, Ni XW, Zhang LS (2014) Effect of hydraulic hysteresis on shear strength of partially saturated clay and its prediction using a water retention surface. Engineering Geology 173:66-73

6. De Souza EJ, Gap L, McCarthy TJ, Arzt E, Crosby AJ (2008) Effect of contact angle hysteresis on the measurement of capillary forces. Langmuir 24(4):1391-1396

7. Desrues J, Chambon R, Mokni M, Mazerolle F (1996) Void ratio evolution inside shear bands in triaxial sand specimens studied by computed tomography. Géotechnique 46(3):539-546

8. Feia S, Ghabezloo S, Bruchon JF, Sulem J, Canou J, Dupla JC (2014) Experimental evaluation of the pore-access size distribution of sands. Geotechnical Testing Journal 37(4):613-620

9. Fredlund DG, Xing A, Fredlund MD, Barbour SL (1995) The relationship of the partially saturated soil shear strength to the soil-water characteristic curve. Canadian Geotechnical Journal 33(3):440-448

10. Gallage CPK, Uchimura T (2010) Effects of dry density and grain size distribution on soil-water characteristic curves of sandy soils. Soils and Foundations 50(1):161-172

11. Gallipoli D, Wheeler S, Karstunen M (2003) Modelling the variation of degree of saturation in a deformable partially saturated soil. Géotechnique 53(1):105-112

12. Gvirtzman H, Magaritz M, Klein E, Nadler A (1983) A scanning electron microscopy study of water in soil. Transport in Porous Media 2:83-93

13. Haines WB (1930) Studies in the physical properties of soil - V: The hysteresis effect in capillary properties and the modes of water distribution associated therewith. Journal of Agricultural Science 20(1):97-116

14. Hamamoto S, Moldrup P, Kawamoto K, Sakaki T, Nishimura T, Komatsu T (2016) Pore network structure linked by X-ray CT to particle characteristics and transport parameters. Soils and Foundations 56(4):676-690

15. Haralick, RM, Sternberg, SR, Zhuang, X (1987) Image analysis using mathematical morphology. IEEE transactions on pattern analysis and machine intelligence 9(4):532-550

16. Hashemi MA, Khaddour G, François B, Massart TJ, Salager S (2014) A tomographic imagery segmentation methodology for three phase geomaterials based on simultaneous region growing. Acta Geotechnica 9(5):831846

17. Higo Y, Oka F, Kimoto S, Sanagawa T, Matsushima Y (2011) Study of strain localization and microstructural changes in partially saturated sand during triaxial tests using microfocus X-ray CT. Soils and Foundations 
51(1):95-111

18. Higo Y, Oka F, Sato T, Matsushima Y, Kimoto S (2013) Investigation of localized deformation in partially saturated sand under triaxial compression by microfocus X-ray CT with digital image correlation. Soils and Foundations 53(2):181-198

19. Higo Y, Oka F, Morishita R, Matsushima Y, Yoshida T (2014) Trinarization of $\mu X$-ray CT images of partially saturated sand at different water retention states using a region growing method. Nuclear Instruments and Methods in Physics Research B 324:63-69

20. Higo Y, Morishita R, Kido R, Khaddour G, Salager S (2015a) Local water retention behavior of sand during drying and wetting process observed by micro x-ray tomography with trinarization. The 15th Asian Regional Conference on Soil Mechanics and Geotechnical Engineering, Japanese Geotechnical Society Special publication 2(16):635638

21. Higo Y, Oka F, Morishita R, Matsushima Y (2015b) Quantitative observation of strain localisation in a partially saturated triaxial specimen using microfocus X-ray CT with image analysis. In: proceedings of the 10th International Workshop on Bifurcation and Degradation in Geomaterials:325-330

22. Higo Y, Kido R, Takamura F, Fukushima Y (2018) Pore-scale investigations of partially water-saturated granular soil. Mechanics Research Communications 94:1-7

23. Khaddour G, Salager S, Higo Y, Andò E, Desrues J (2015) Discrete analysis of water phase evolution within unsaturated soil. In: proceedings of the 2nd International Conference on Tomography of Materials and Structures, 30th June-3rd July 2015, Quebec, Canada

24. Khaddour G, Riedel I, Ando E, Charrier P, Besuelle P, Desrues J, Viggiani G, Salager S (2018) Grain-scale characterization of water retention behaviour of sand using X-ray CT. Acta Geotechnica 13:497-512

25. Kido R, Higo Y (2017a) Evaluation of distribution of void ratio and degree of saturation in partially saturated triaxial sand specimen using micro x-ray tomography. Japanese Geotechnical Society Special Publication 5(2):2227

26. Kido R, Higo Y, Salager S (2017b) Microscopic investigation of progressive changes of pore water distribution in shear band of unsaturated sand under triaxial compression. In: proceedings of the 19th International Conference on Soil Mechanics and Geotechnical Engineering:1171-1174

27. Kido R, Higo Y (2019) Distribution changes of grain contacts and menisci in shear band during triaxial compression test for unsaturated sand. Japanese Geotechnical Society Special Publication 7(2):627-635

28. Kim FH, Penumadu D, Hussey DS (2012) Water distribution variation in partially saturated granular materials using neutron imaging. Journal of Geotechnical and Geoenvironmental engineering 138(2):147-154

29. Kim FH, Penumadu D, Gregor J, Kardjilov N, Manke L (2013) High-resolution neutron and X-ray imaging of granular materials. Journal of Geotechnical and Geoenvironmental engineering 139(5):715-723

30. Kohgo Y, Nakano M, Miyazaki T (1993) Theoretical aspects of constitutive modelling for partially saturated soils. Soils and Foundations 33(4):49-63

31. Lai Z, Chen Q (2019) Reconstructing granular particles from X-ray computed tomography using the TWS 
machine learning tool and the level set method. Acta Geotechnica 14:1-18

32. Manahiloh KN, Meehan CL (2017) Determining the soil water characteristic curve and interfacial contact angle from microstructural analysis of X-ray CT images. Journal of Geotechnical and Geoenvironmental Engineering 143(8):1-11

33. Mašín D (2010) Predicting the dependency of a degree of saturation on void ratio and suction using effective stress principle for partially saturated soils. International Journal for Numerical and Analytical Methods in Geomechanics 34(1):73-90

34. Moro F, Böhni H (2002) Ink-bottle effect in mercury intrusion porosimetry of cement-base materials. Journal of Colloid and Interface Science 246:135-149

35. Mukunoki T, Miyata Y, Mikami K, Shiota E (2016) X-ray CT analysis of pore structure in sand. Solid Earth 7(3):929-942

36. Nguyen CD, Benahmed N, Andò E, Sibille L, Philippe P (2019) Experimental investigation of microstructural changes in soils eroded by suffusion using X-ray tomography. Acta Geotechnica 14: 749-765

37. Oda M, Takemura T, Takahashi M (2004) Microstructure in shear band observed by microfocus X-ray computed tomography. Géotechnique 54(8):539-542

38. Prapaharan S, Altschaeffl AG, Dempsey BJ (1985) Moisture curve of a compacted clay: mercury intrusion method. Journal of Geotechnical Engineering 111(9):1139-1143

39. Romero E, Gens A, Lloret A (1999) Water permeability, water retention and microstructure of unsaturated compacted Boom clay. Engineering Geology 54(1-2):117-127

40. Romero E, Simms PH (2008) Microstructure investigation in unsaturated soils: a review with special attention to contribution of mercury intrusion porosimetry and environmental scanning electron microscopy. Geotechnical and Geological Engineering 26(6):705-727

41. Scheel M, Seemann R, Brinkmann M, Di Michiel M, Sheppard A, Breidenbach B, Herminghaus S (2008) Morphological clues to wet granular pile stability. Nature Materials 7:189-193

42. Sun D, Sun W, Xiang L (2010) Effect of degree of saturation on mechanical behaviour of unsaturated soils and its elastoplastic simulation. Computers and Geotechnics 37:678-688

43. Vachaud G, Thony JL (1971) Hysteresis during infiltration and redistribution in a soil column at different initial water contents. Water Resources Research 7(1):111-127

44. Van Genuchten MT (1980) A closed-form equation for predicting the hydraulic conductivity of partially saturated soil. Soil Science Society of America Journal 44(5):892-898

45. Vanapalli SK, Nicotera MV, Sharma RS (2008) Axis translation and negative water column techniques for suction control. Geotechnical and Geological Engineering 26:645-660

46. Wang JP, Lambert P, De Kock T, Cnudde V, François B (2019) Investigation of the effect of specific interfacial area on strength of unsaturated granular materials by X-ray tomography. Acta Geotechnica 14:1545-1559 
1

2

3

4

$5468 \quad$ List of Tables

6

7

8

9469 Table 1. Physical properties of Toyoura sand

470 Table 2. Specimen conditions

474 Table 1. Physical properties of Toyoura sand

Particle density $\left(\mathrm{g} / \mathrm{cm}^{3}\right) \quad 2.64$

Maximum void ratio $\quad 0.975$

Minimum void ratio $\quad 0.614$

Average diameter (mm) $\quad 0.185$

Uniformity coefficient $\quad 1.6$

Fines content $(\%) \quad 0.1$

476 Table 2. Specimen conditions

\begin{tabular}{lc}
\hline Diameter (mm) & 18.00 \\
Height $(\mathrm{mm})$ & 17.74 \\
Initial void ratio & 0.822 \\
Initial porosity (\%) & 45.12 \\
Relative density $D_{\mathrm{r}}(\%)$ & 42.38 \\
Initial degree of saturation (\%) & 100.00 (Assumption) \\
\hline
\end{tabular}

471 Table 3. Specifications of microfocus x-ray apparatus installing FPD

472 Table 4 Validation results for CT images with different resolutions 
1

2

3

4

478

6

7

8

9479

10

11

12

13

14

15

16

17

18

19

20

21

22

23

24

25

26

27

28

29480

30

31

32481

33

34

35

36
Table 3. Specifications of microfocus x-ray CT apparatus

\begin{tabular}{l|lc}
\hline & Max. voltage $(\mathrm{kV})$ & 225 \\
X-ray & Max. current $(\mathrm{mA})$ & 0.888 \\
source & Max. consumption power $(\mathrm{W})$ & 200 \\
& Min. focus size $(\mu \mathrm{m})$ & 4 \\
\hline \multirow{2}{*}{ Flat } & Image matrices & $1024^{2}$ \\
panel & Resolution performance $(\mu \mathrm{m})$ & 5 \\
detector & Integration time $(\mathrm{ms})$ & $66-999$ \\
(FPD) & Projection views & $600-4800$ \\
& Number of images averaged at & $1-50$ \\
\hline
\end{tabular}

Table 4 Validation results for CT images with different resolutions

\begin{tabular}{|c|c|c|c|}
\hline & Measured value & \multicolumn{2}{|c|}{ Trinarization } \\
\hline Case & Specimen & A & B \\
\hline Void ratio & 0.846 & 0.831 & 0.820 \\
\hline Degree of saturation & 0.662 & 0.656 & $0.725^{483}$ \\
\hline Water content & 0.212 & 0.206 & 0.225 \\
\hline
\end{tabular}


1

2

3

8

\section{List of Figures}

488 Fig. 2 Schematic illustration of test apparatus and negative water column

489 Fig. 3 Scan area and conditions

490 Fig. 4 Gray value distributions obtained by maximum likelihood evaluation: (a) assumption of gray value distributions

491 as normal and uniform distributions and (b) superposition of gray value distributions

493 Fig. 6 Horizontal cross section of trinarized image

494 Fig. 7 Validation of trinarization technique: (a) specimen and (b) application of trinarization to CT images

495 Fig. 8 Gray value histograms for CT images: (a) Case A (6.72 $\mu \mathrm{m}$ in resolution) and (b) Case B (12.25 $\mu \mathrm{m}$ in resolution)

496 Fig. 9 Procedure for morphology analysis of pore water phase

497 Fig. 10 Water retention curve

498 Fig. 11 Horizontal and vertical cross sections of original CT images and trinarized images

500 Fig. 13 Comparison of water retention curve with those calculated using trinarization

501 Fig. 14 Cluster volume distribution curves: (a) pore air and (b) pore water 
1

2

3

4

5502

6

7

8

9503 10

11

12

Fig. 15 Maximum volume of clusters at different degrees of saturation: (a) pore air and (b) pore water

504 Fig. 17 3D and 2D views of pore water clusters for different levels of continuity

505 Fig. 18 Pore water clusters with different volumes at grain contacts (point "e")

508 Fig. 21 Continuity of clusters at different degrees of saturation: (a) pore air and (b) pore water

509 Fig. 22 Number of clusters at different degrees of saturation: (a) pore air and (b) pore water

Fig. 23 Summary of morphology analysis 


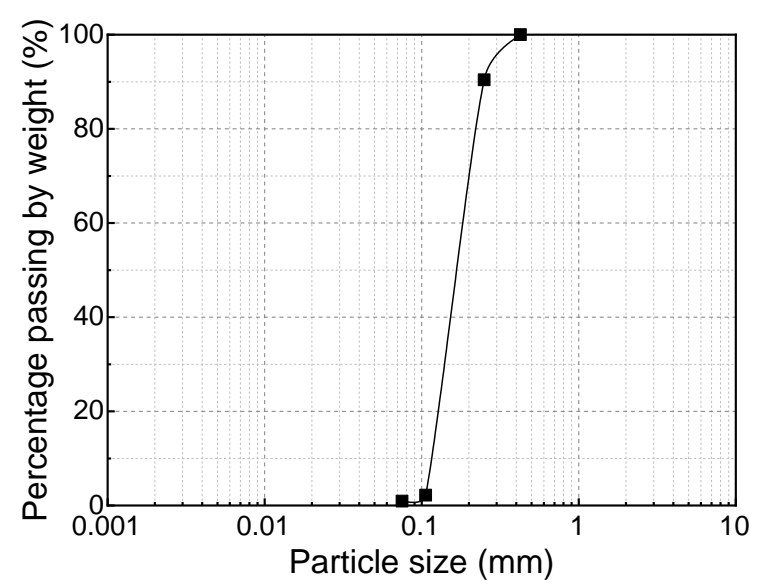

Fig. 1 Grain size distribution curve of Toyoura sand

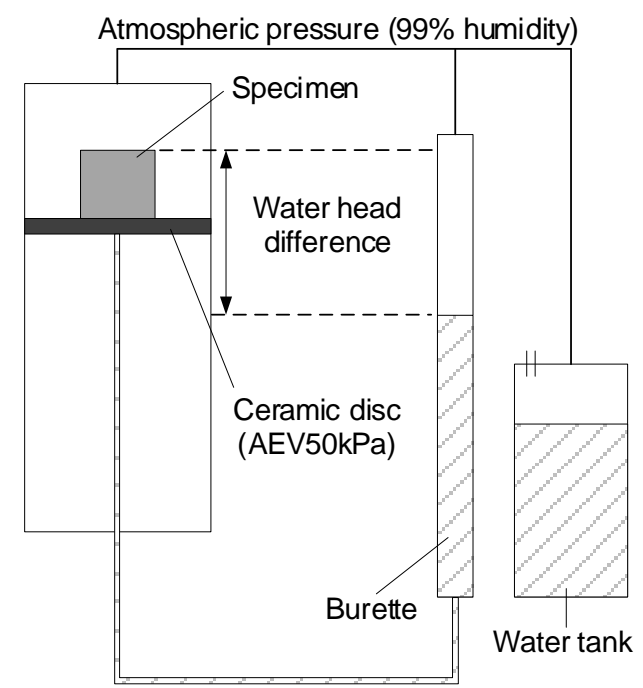

Fig. 2 Schematic illustration of test apparatus and negative water column 


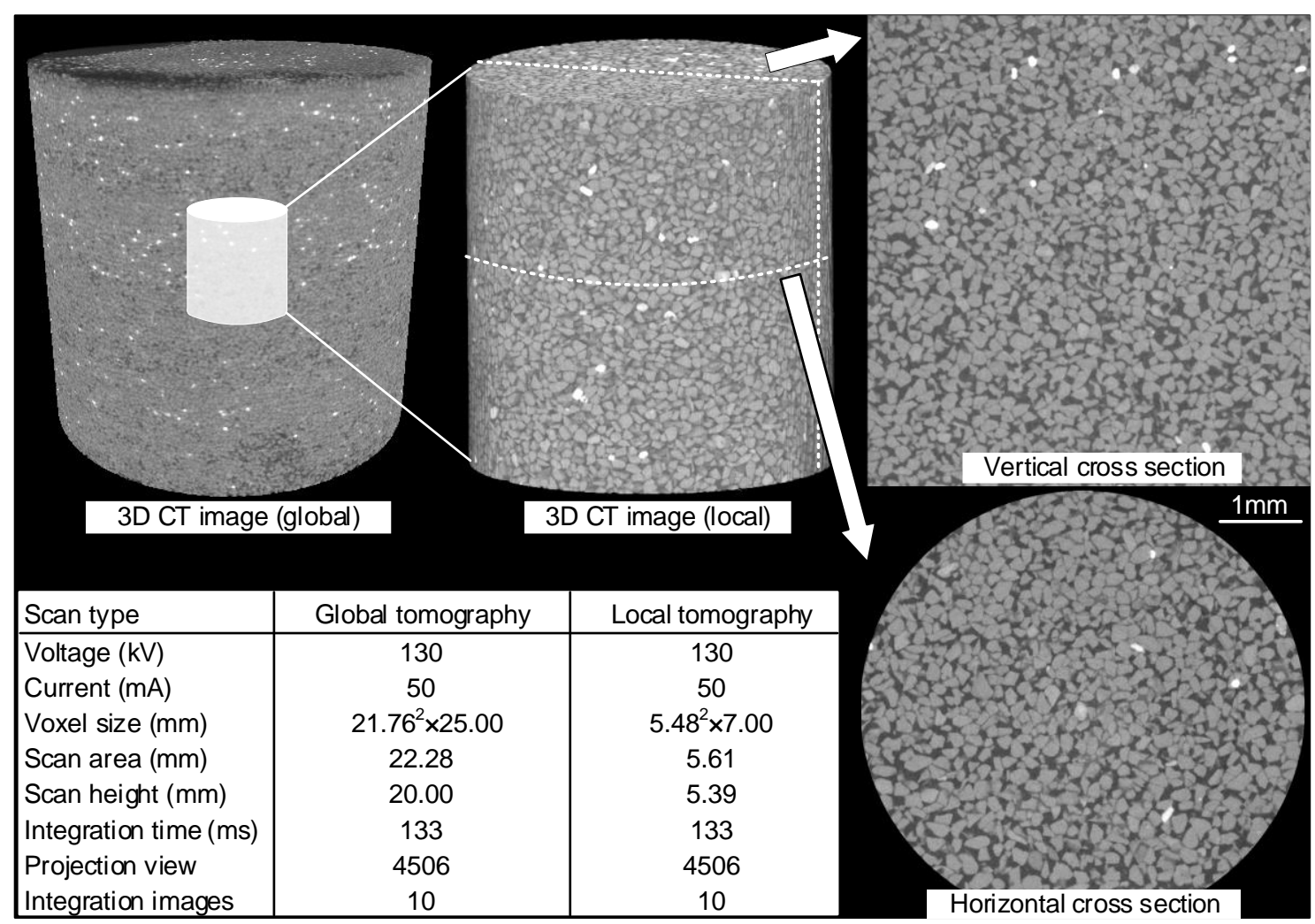

Fig. 3 Scan area and conditions
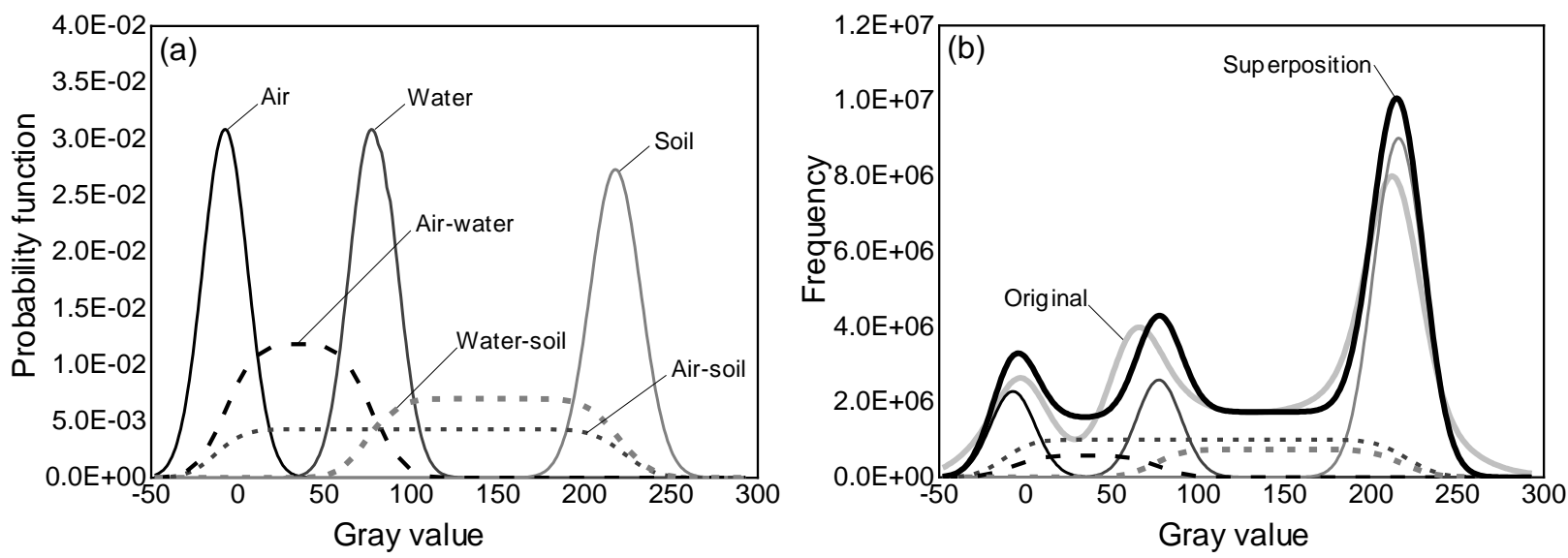

Fig. 4 Gray value distributions obtained by maximum likelihood evaluation:

(a) assumption of gray value distributions as normal and uniform distributions and (b) superposition of gray value distributions 


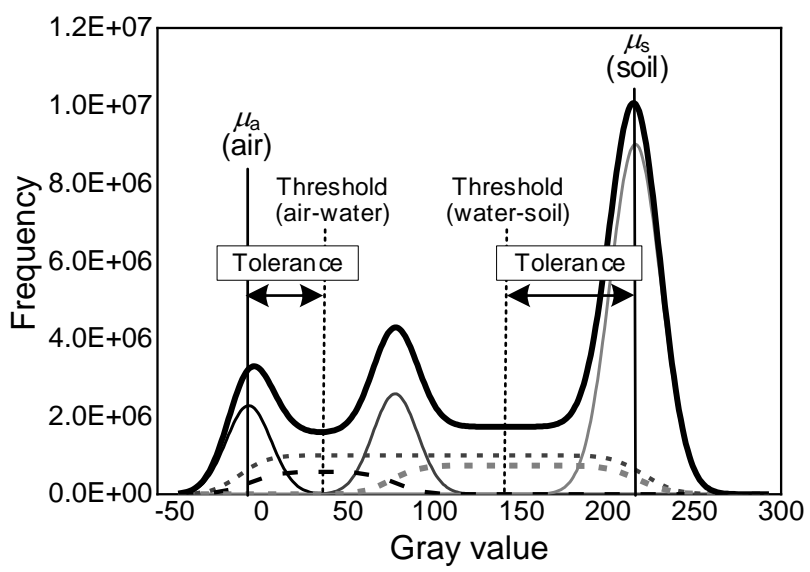

Fig. 5 Conceptual diagram of determination of tolerances for region growing

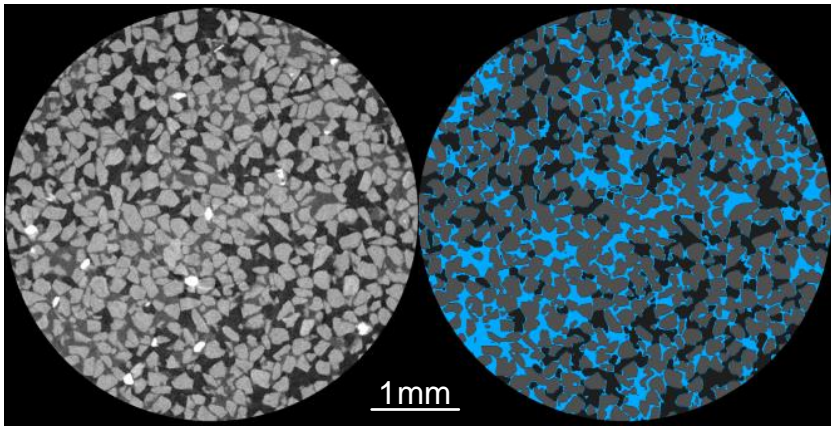

air $\square$ Water $\square$ Soil $\quad$ Air $\square$ Water $\square$ Soil

Fig. 6 Horizontal cross section of trinarized image

(a)

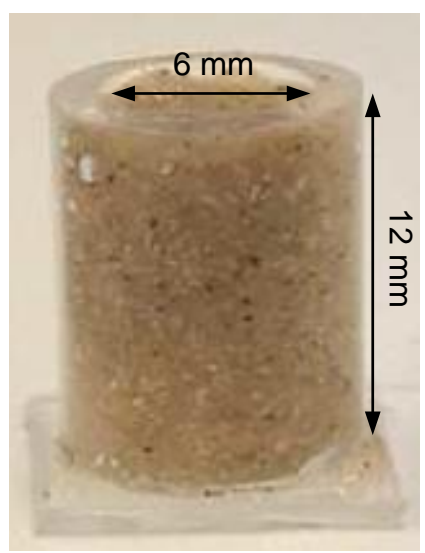

(b)
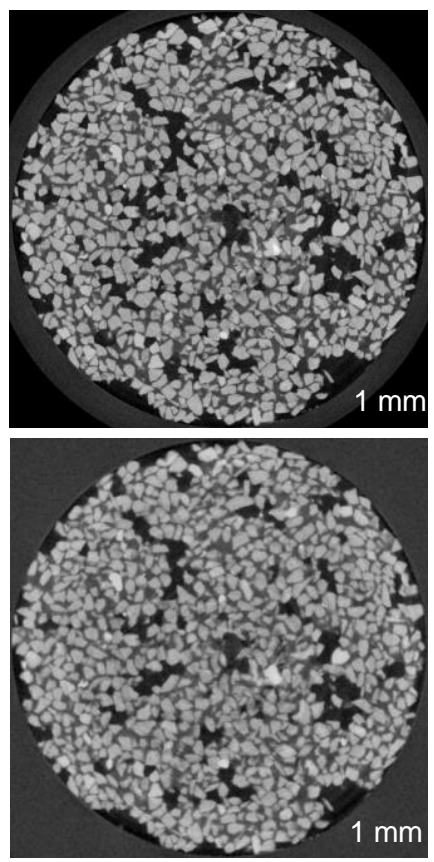

[Case A]

$6.72 \mathrm{~mm}$

in resolution

Trinarization
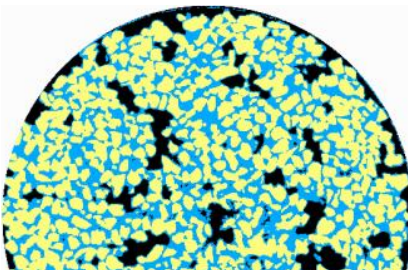

[Case B]

$12.25 \mathrm{~mm}$

in resolution

Trinarization

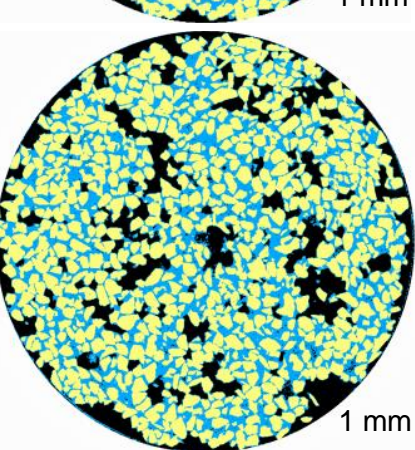

Fig. 7 Validation of trinarization technique: (a) specimen and (b) application of trinarization to CT images 

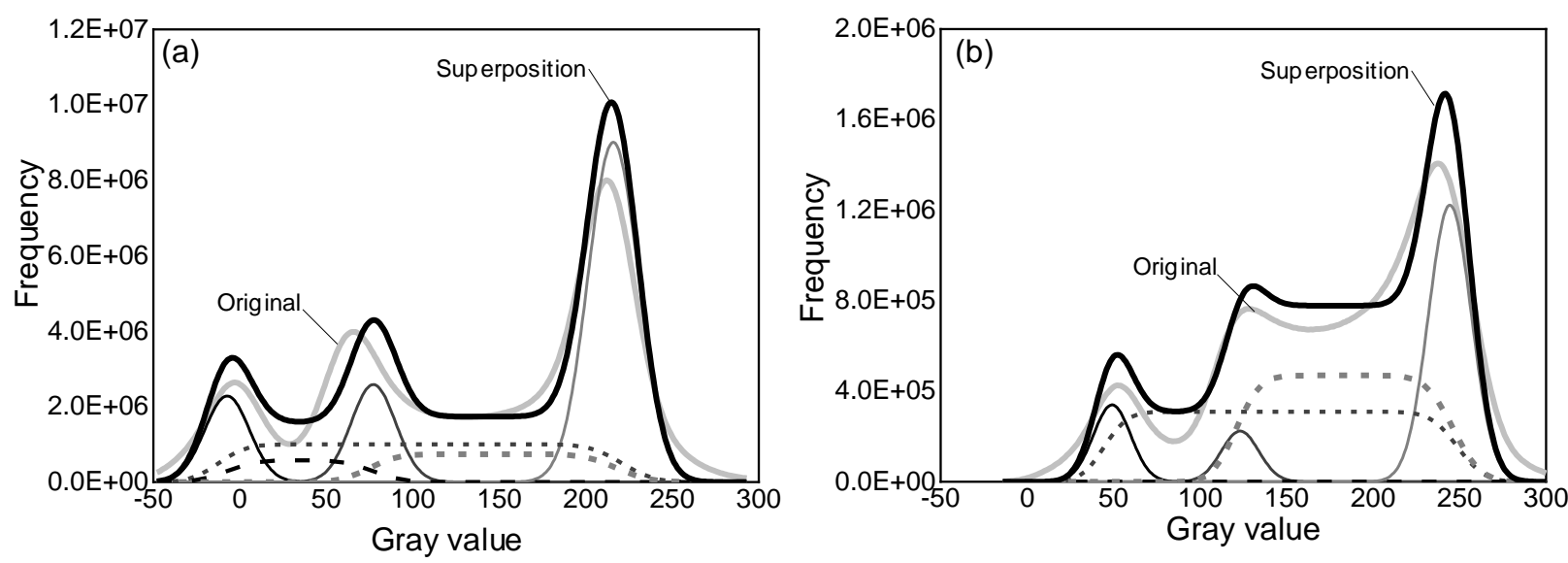

Fig. 8 Gray value histograms for CT images: (a) Case A $(6.72 \mu \mathrm{m}$ in resolution) and (b) Case B (12.25 $\mu \mathrm{m}$ in resolution)

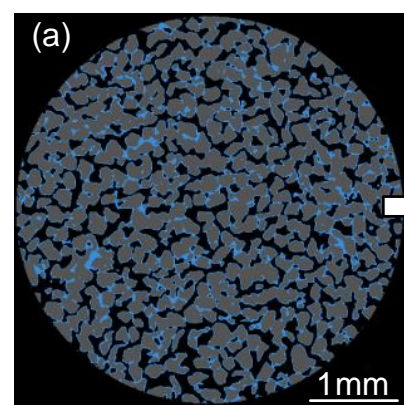

Trinarized image

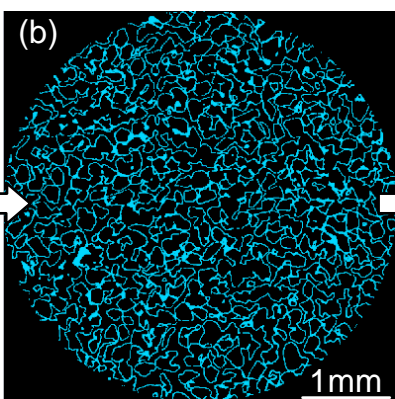

Binary image of pore water

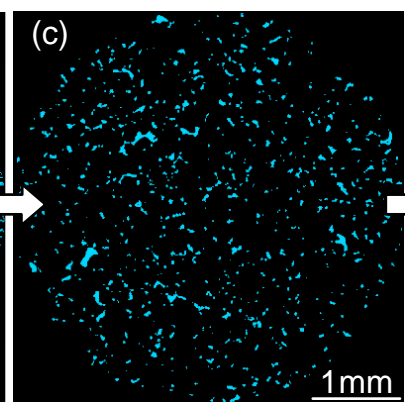

Eroded \& dilated image

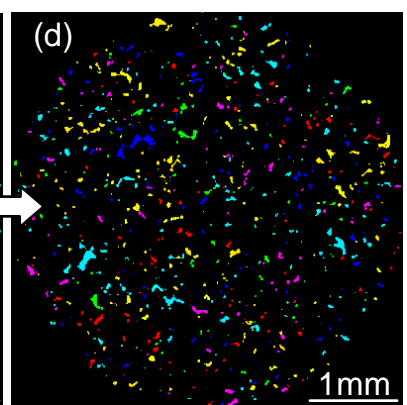

Labeled image

Fig. 9 Procedure for morphology analysis of pore water phase

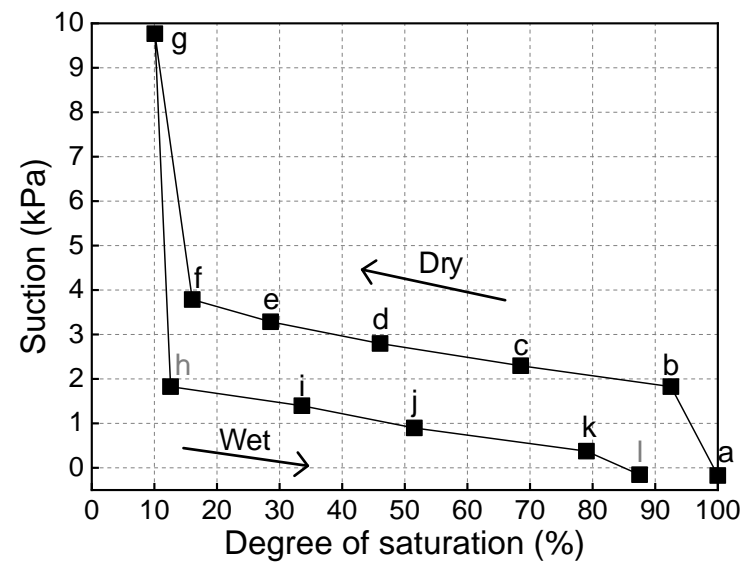

Fig. 10 Water retention curve 


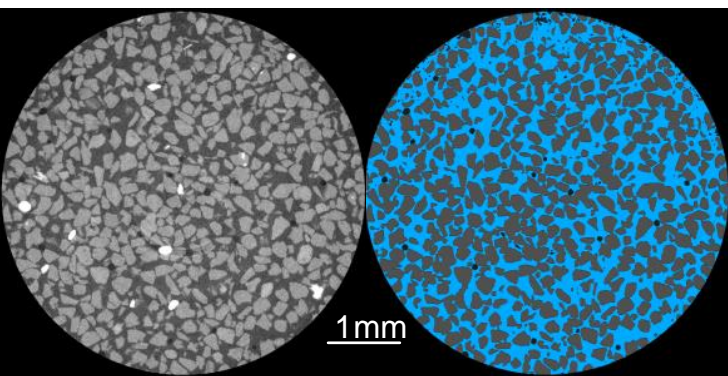

Point a (global degree of saturation $\fallingdotseq 100.00 \%$ )

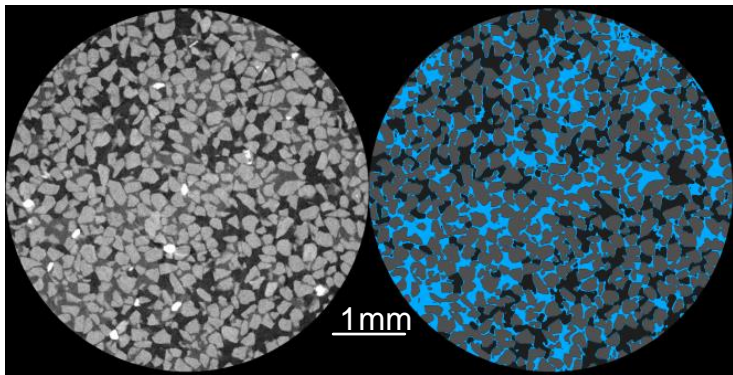

Point $d$ (global degree of saturation $=46.05 \%$ )

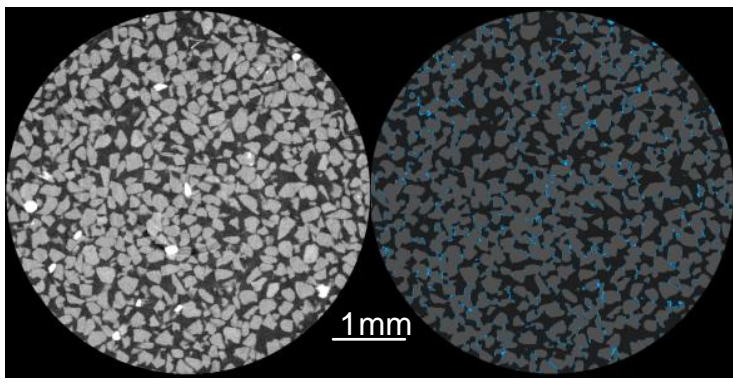

Point $\mathrm{f}$ (global degree of saturation=16.07\%)

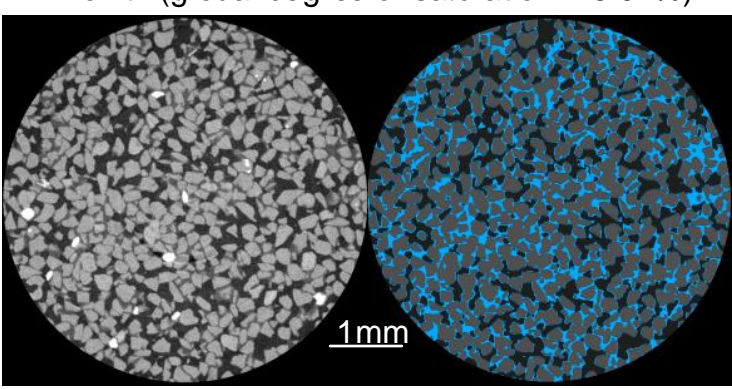

Point i (global degree of saturation $=33.56 \%$ )

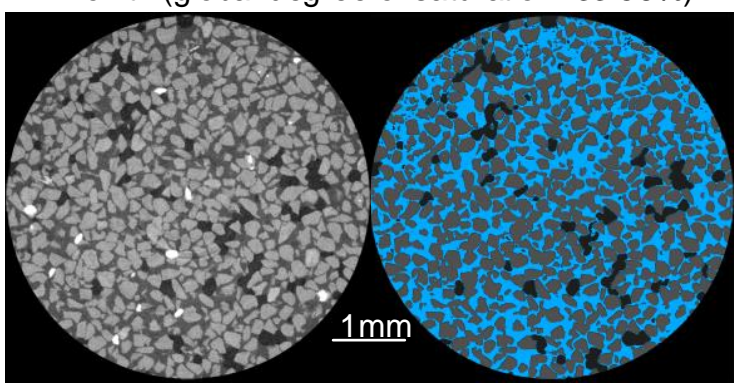

Point k (global degree of saturation=79.02\%)

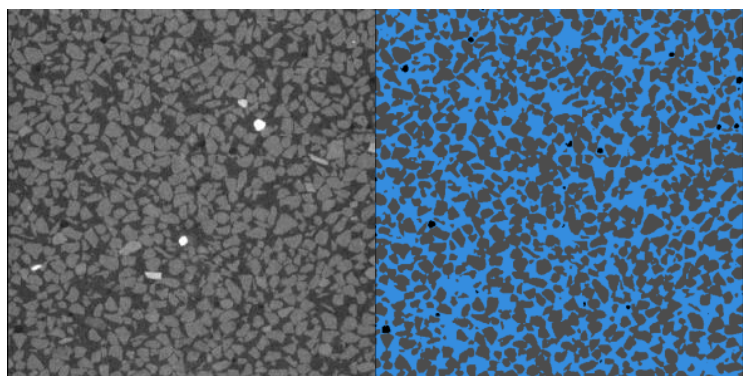

Point a (global degree of saturation $\fallingdotseq 100.00 \%$ )

Drying

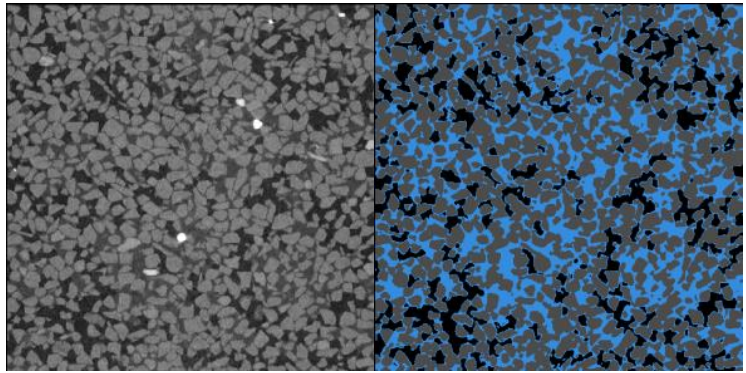

Point d (global degree of saturation=46.05\%)

Drying

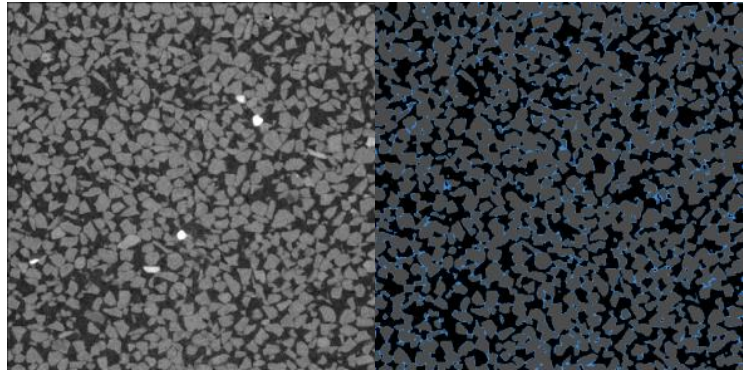

Point $\mathrm{f}$ (global degree of saturation $=16.07 \%$ )

Ve

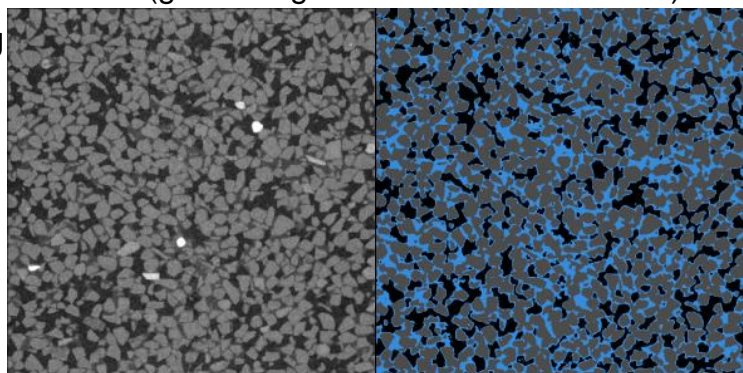

Point $\mathrm{i}$ (global degree of saturation $=33.56 \%$ )

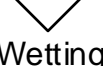

Wetting

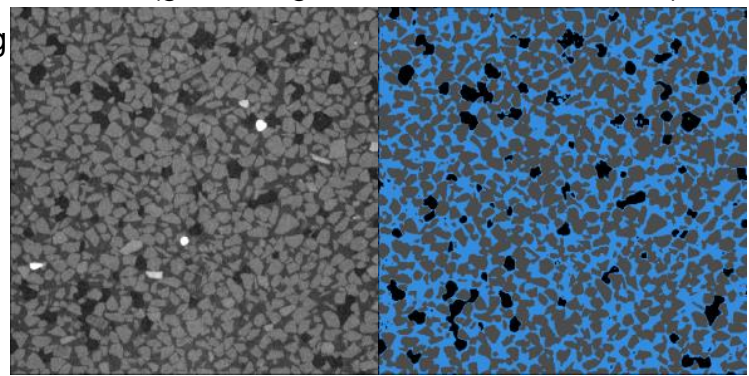

Point $\mathrm{k}$ (global degree of saturation=79.02\%)

Fig. 11 Horizontal and vertical cross sections of original CT images and trinarized images 


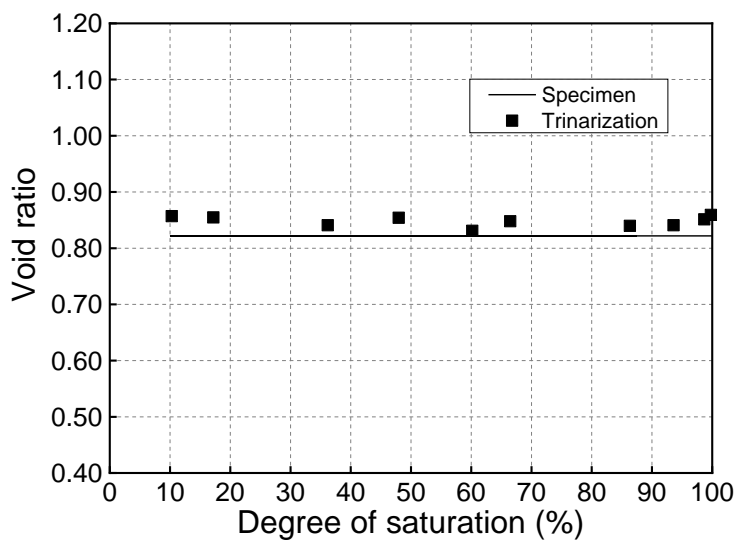

Fig. 12 Local void ratios at different degrees of saturation

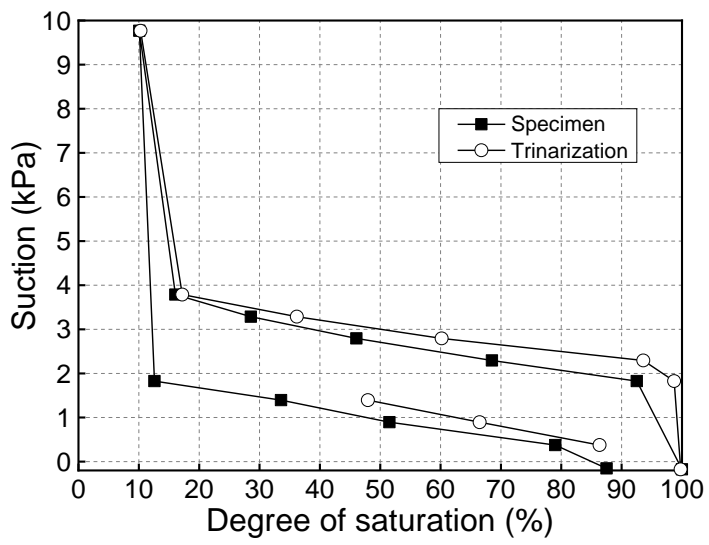

Fig. 13 Comparison of water retention curve with those calculated using trinarization
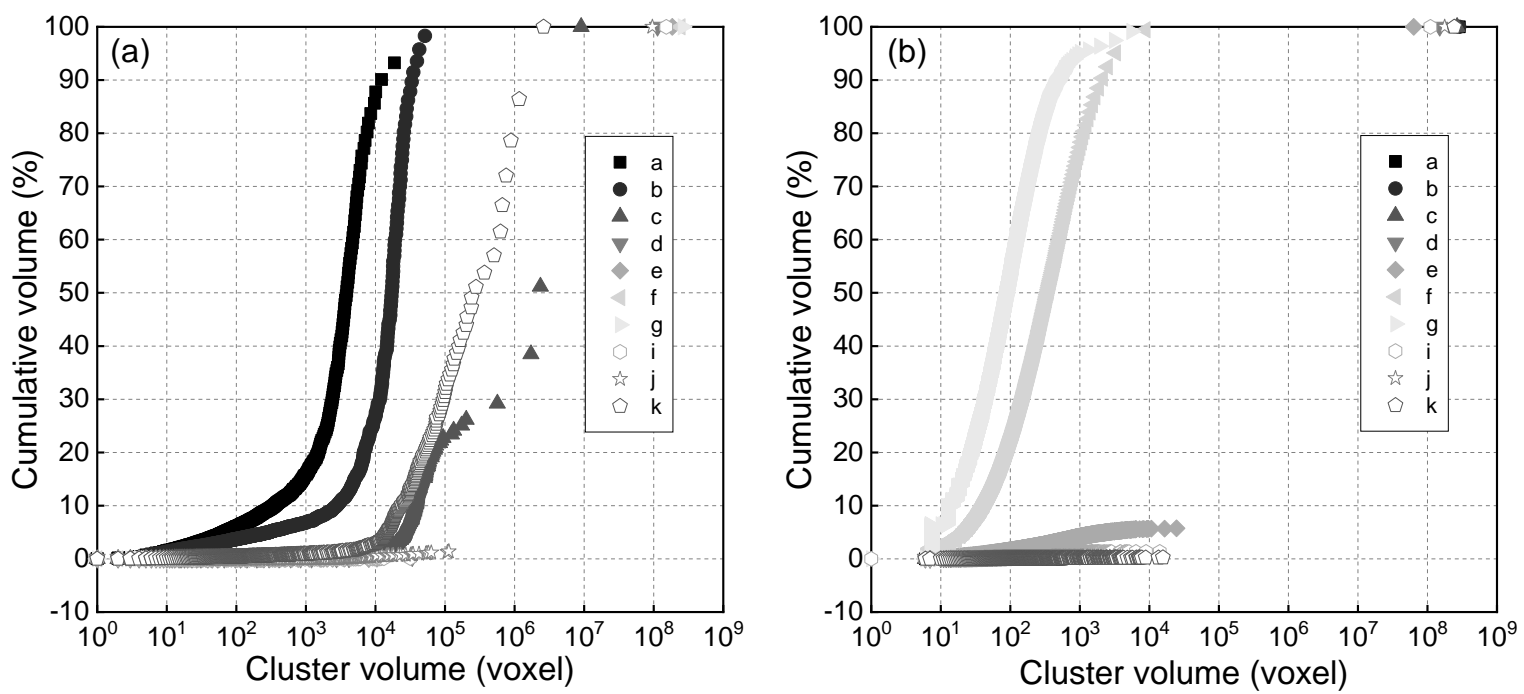

Fig. 14 Cluster volume distribution curves: (a) pore air and (b) pore water 

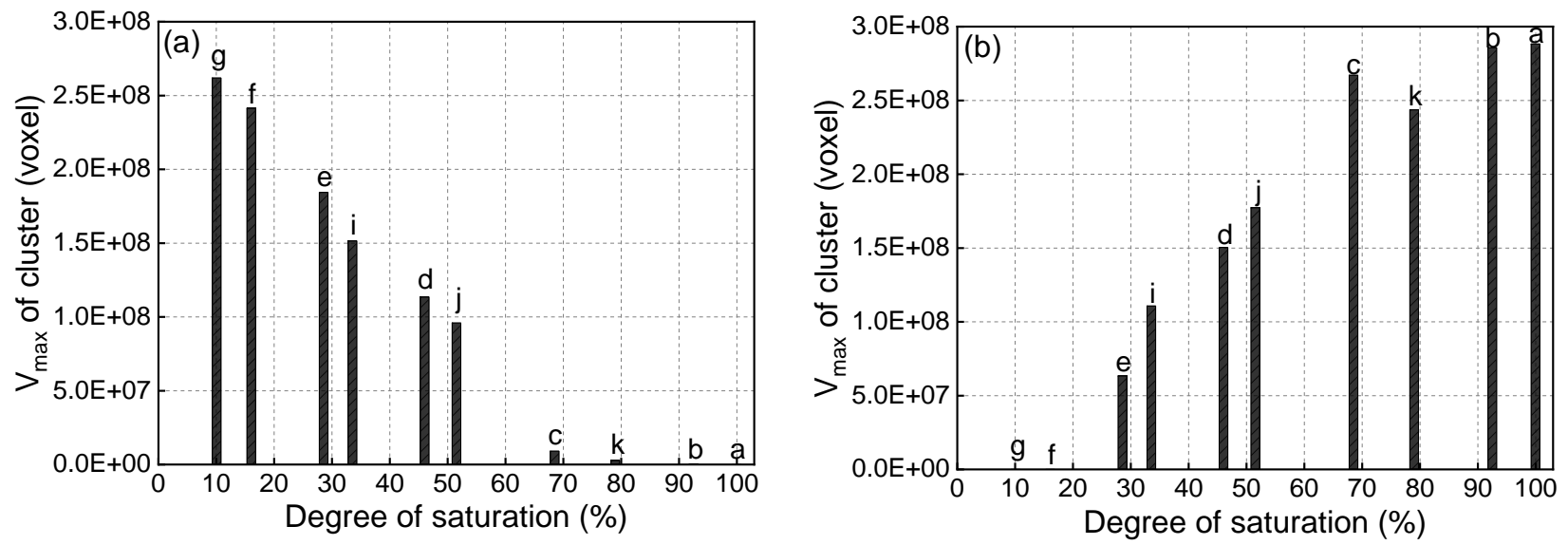

Fig. 15 Maximum volume of clusters at different degrees of saturation: (a) pore air and (b) pore water
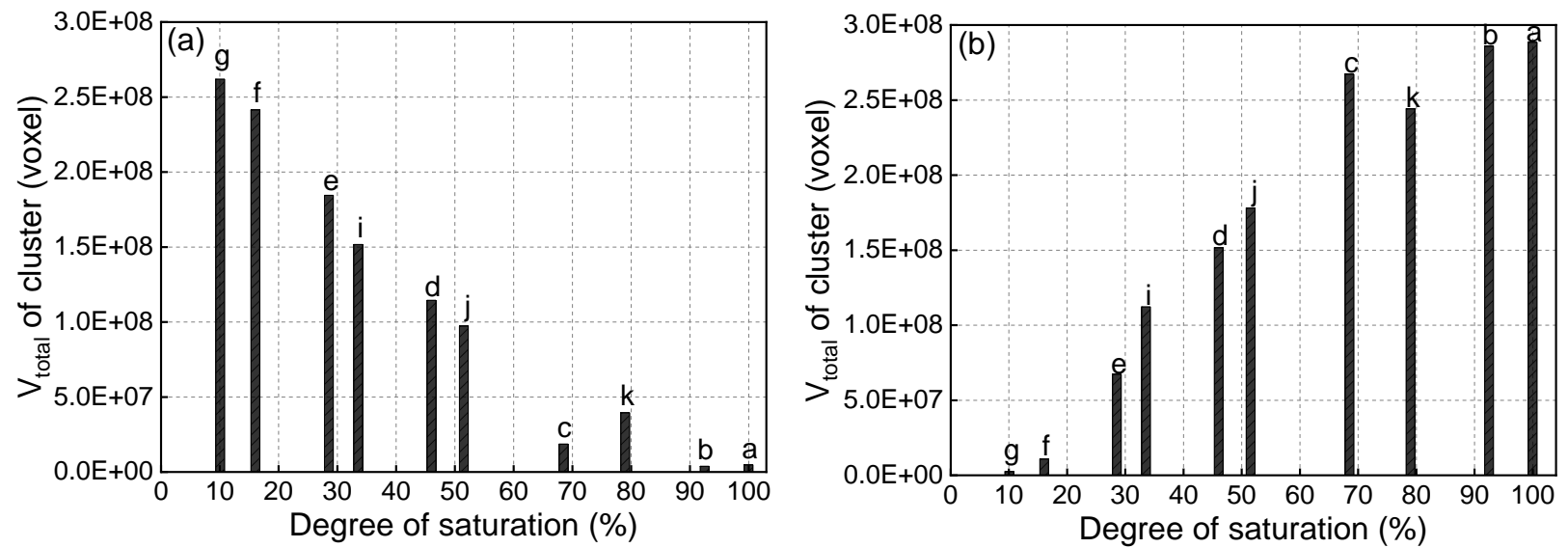

Fig. 16 Total volume of clusters at different degrees of saturation: (a) pore air and (b) pore water 


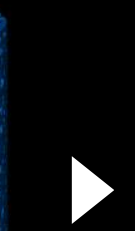

Decrease in continuity

3D view

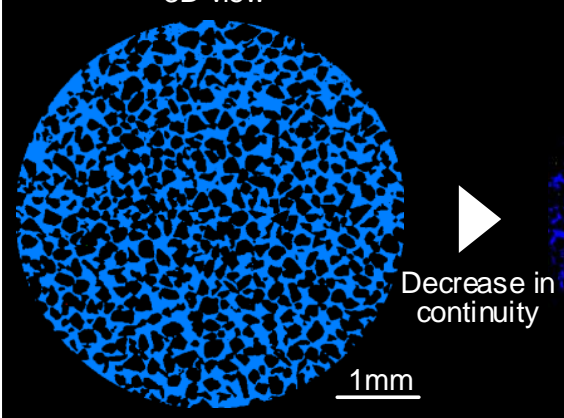

$2 \mathrm{D}$ view

A continuous cluster \& small volume clusters

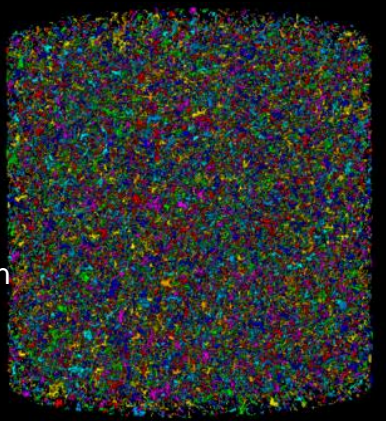

3D view

3D view

Decrease in continuity

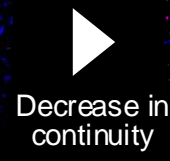

$1 \mathrm{~mm}$

$1 \mathrm{~mm}$

$2 \mathrm{D}$ view

Small volume clusters

(c) Continuity is $0.10 \%$ (point f: $S_{r}=16.07 \%$ )

(a) Continuity is almost $100 \%$ (point a: $S_{\mathrm{r}}=100 \%$ ) (b) Continuity is $97.26 \%$ (point e: $S_{r}=28.56 \%$ )

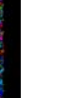

Fig. $173 \mathrm{D}$ and 2D views of pore water clusters for different levels of continuity

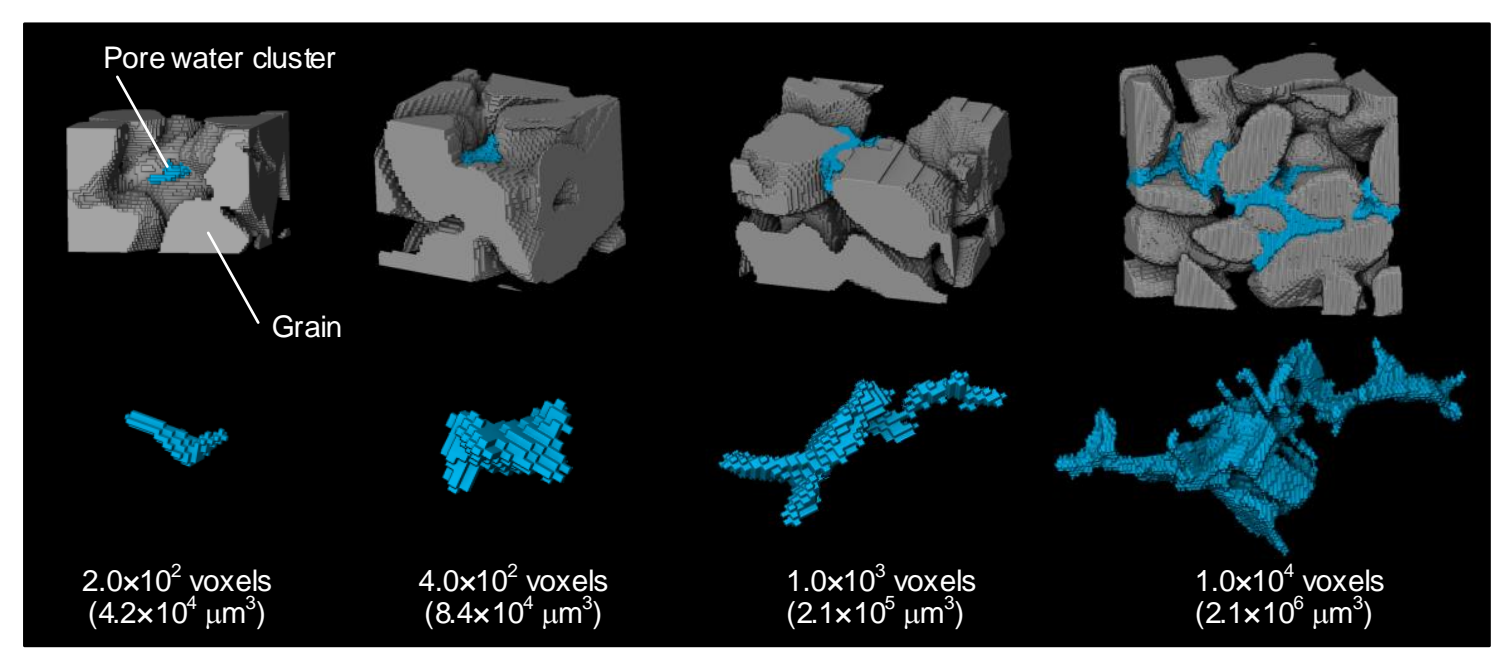

Fig. 18 Pore water clusters with different volumes at grain contacts (point “e”) 


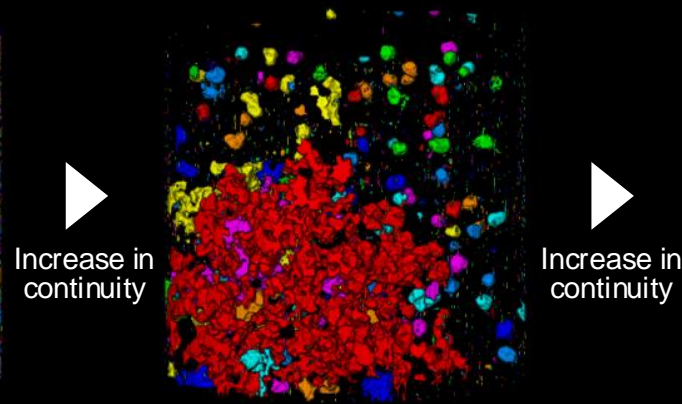

3D view

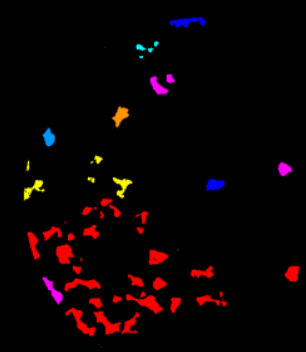

2D view

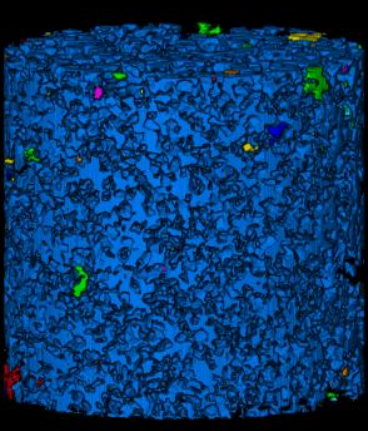

3D view

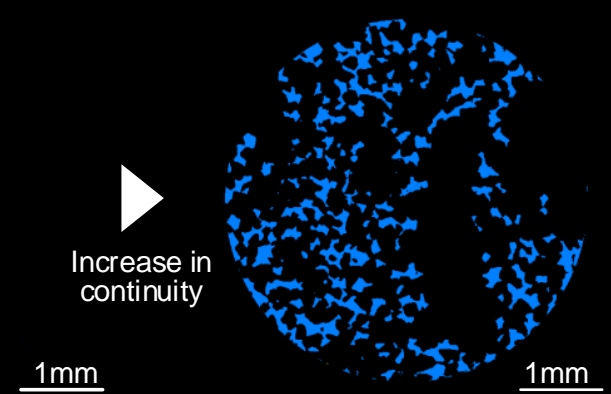

$2 \mathrm{D}$ view

Small volume clusters

A continuous cluster \& small volume clusters

A continuous cluster
(a) Continuity is $1.71 \%$
(point b: $S_{r}=92.51 \%$ )
(b) Continuity is $48.82 \%$ (point c: $S_{\mathrm{r}}=68.53 \%$ )
(c) Continuity is $99.24 \%$ (point d: $S_{\mathrm{r}}=46.05 \%$ )

Fig. 19 3D and 2D views of pore air clusters for different levels of continuity

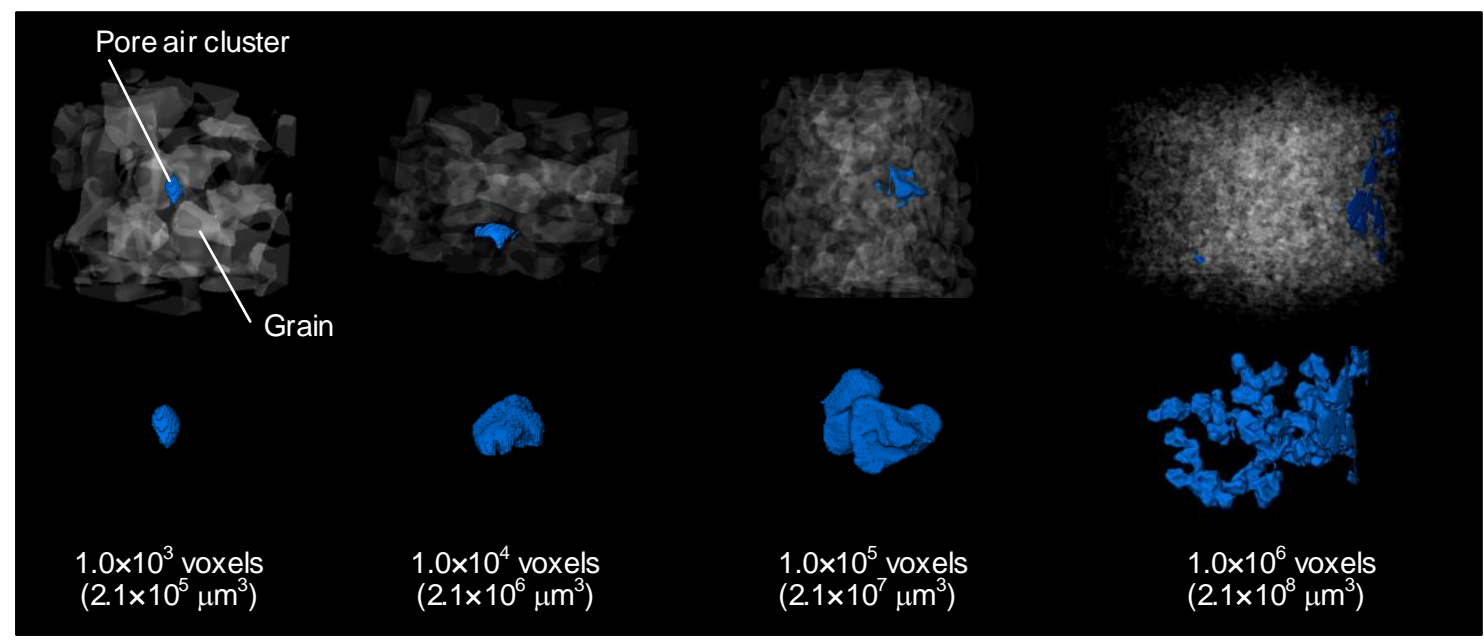

Fig. 20 Pore air clusters with different volumes (point "c") 

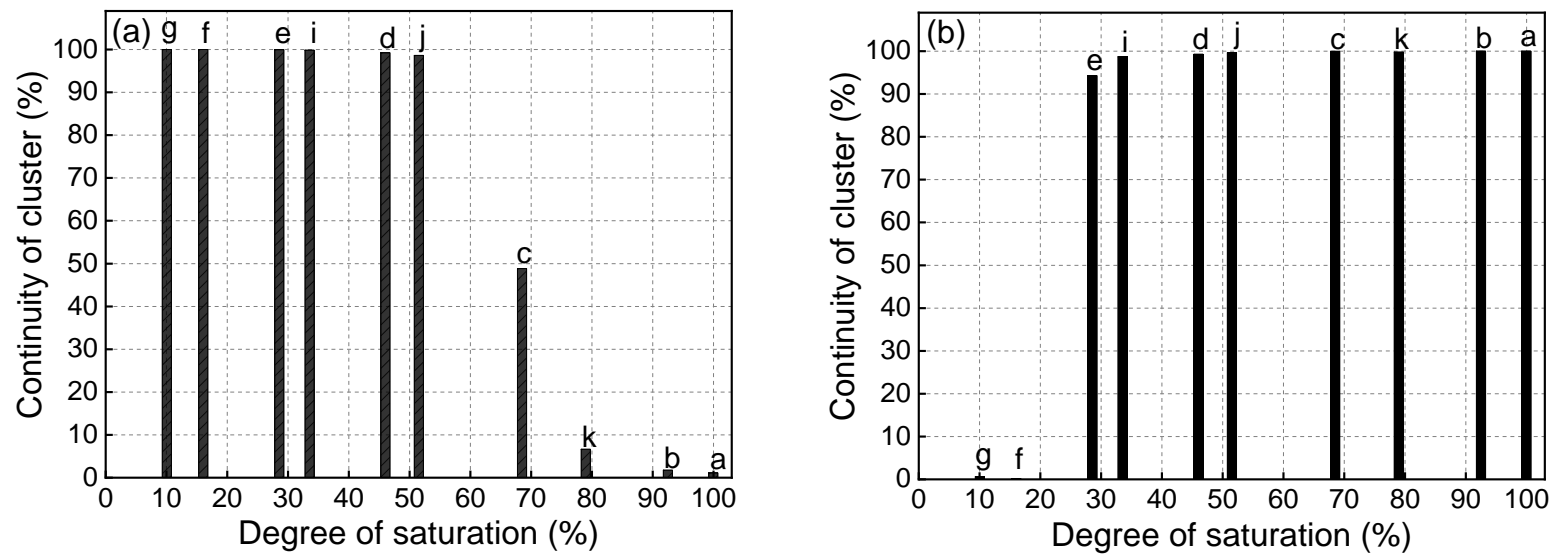

Fig. 21 Continuity of clusters at different degrees of saturation: (a) pore air and (b) pore water
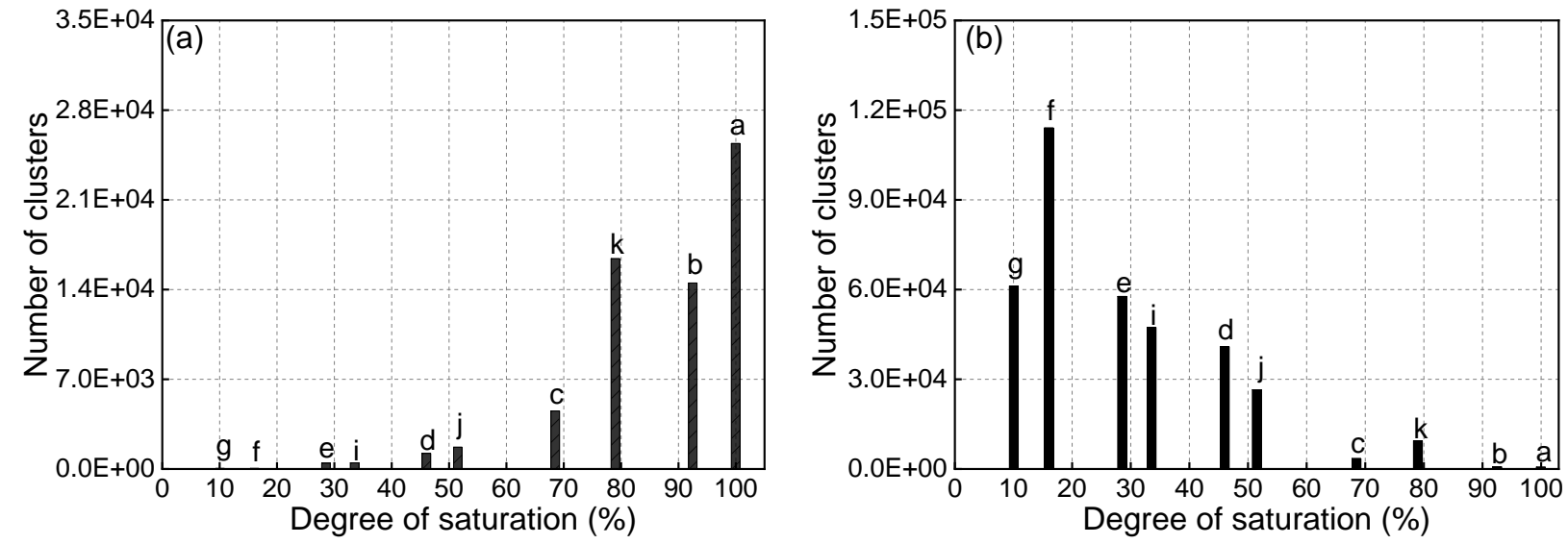

Fig. 22 Number of clusters at different degrees of saturation: (a) pore air and (b) pore water 


\begin{tabular}{|c|c|c|c|c|c|c|c|c|c|c|c|c|c|}
\hline Process & \multicolumn{7}{|c|}{ Drying } & \multicolumn{6}{|c|}{ Wetting } \\
\hline Points & a & b & c & $d$ & e & $f$ & g & $\mathrm{h}$ & i & j & k & I & $\mathrm{m}$ \\
\hline Global $S_{r}(\%)$ & 100 & 92.51 & 68.53 & 46.05 & 28.56 & 16.07 & 10.08 & & 33.56 & 51.54 & 79.02 & & \\
\hline $\begin{array}{c}\text { Continuity } \\
\text { (air) }\end{array}$ & \multicolumn{2}{|c|}{ Discontinuous } & \multicolumn{3}{|c|}{ Continuous } & \multicolumn{2}{|c|}{ Continuous } & & \multicolumn{2}{|c|}{ Continuous } & \begin{tabular}{|l|} 
Discon- \\
tinuous
\end{tabular} & & \\
\hline $\begin{array}{c}\text { Continuity } \\
\text { (water) }\end{array}$ & \multicolumn{2}{|c|}{ Continuous } & \multicolumn{3}{|c|}{ Continuous } & \multicolumn{2}{|c|}{ Discontinuous } & & \multicolumn{2}{|c|}{ Continuous } & \begin{tabular}{|l|}
$\begin{array}{l}\text { Conti- } \\
\text { nuous }\end{array}$ \\
\end{tabular} & & \\
\hline $\begin{array}{c}\text { Cluster volume } \\
\text { (air) }\end{array}$ & \multicolumn{2}{|c|}{ Small } & \multicolumn{5}{|c|}{ Large } & & \multicolumn{3}{|c|}{ Large } & & \\
\hline $\begin{array}{c}\text { Cluster volume } \\
\text { (water) }\end{array}$ & \multicolumn{5}{|c|}{ Large } & \multirow{2}{*}{\multicolumn{2}{|c|}{ Small }} & & \multicolumn{3}{|c|}{ Large } & & \\
\hline $\begin{array}{l}\text { Number of } \\
\text { clusters (air) }\end{array}$ & \multicolumn{2}{|c|}{ Large } & \multicolumn{3}{|r|}{ Small } & & & & \multicolumn{2}{|c|}{ Small } & Large & & \\
\hline $\begin{array}{c}\text { Number of } \\
\text { clusters (water) }\end{array}$ & \multicolumn{3}{|c|}{ Small } & \multicolumn{4}{|c|}{ Large } & & \multicolumn{2}{|c|}{ Large } & Small & & \\
\hline
\end{tabular}

Note 1: "continuous" means a continuity of nearly $100 \%$, while "discontinuous" means a continuity of nearly $0 \%$.

Note 2: $1.0 \times 10^{6}$ voxels and $1.0 \times 10^{4}$ voxels are thresholds for the air phase and the water phase, respectively, where their morphologies transit from "large cluster volume" to "small cluster volume" and vice versa.

Note 3: Thresholds between "large number of clusters" and "small number of clusters" are $7.0 \times 10^{3}$ (air) and $1.5 \times 10^{4}$ (water), respectively.

Fig. 23 Summary of morphology analysis 